\title{
Haut und Tiere
}

\author{
Bodo Melnik und Heinz Mehlhorn
}

Tiere spielen in der Pathogenese zahlreicher Hautkrankheiten eine bedeutende Rolle. Für den Hautarzt sind klinische Angaben zu vorausgegangenem Tierkontakt von großer klinischer und differenzialdiagnostischer Bedeutung. Tiere können als Vektoren gefährlicher pathogener Krankheitserreger wie Viren, Bakterien, Protozoen, Pilze und Würmer fungieren, Ektoparasiten auf die Haut übertragen, selbst auf beziehungsweise in der Haut parasitieren, aber auch durch Tierallergene und Toxine lokale kutane Intoleranzreaktionen, systemische toxische sowie anaphylaktische Reaktionen mit tödlichem Ausgang herbeiführen $[9,43,111,114]$

Globalisierung, Tourismus und Klimaveränderungen beeinflussen die Epidemiologie der insgesamt 250 bekannten Zoonosen. Bei der Übertragung pathogener Erreger, Auslösung kutaner allergischer und toxischer Intoleranzreaktionen haben Arthropoden für die Dermatologie eine herausragende Bedeutung $[42,43,163]$. Arthropoden sind Invertebraten mit chitinhaltigem Exoskelett, von denen zwei Gruppen, die Arachnida, (unter anderem mit Zecken, Milben, Spinnen, Skorpionen) und Insecta (unter anderem Läuse, Flöhe, Wanzen, Fliegen, Hymenoptera) die Mehrzahl der dermatologisch relevanten, durch Tiere induzierten Krankheiten verursachen [113]. Neue Erkenntnisse in Diagnostik, Therapie, Epidemiologie und Prävention dermatologisch relevanter Arthropoden-vermittelter Erkrankungen im europäischen Raum und Erkrankungen durch gewöhnliche und exotische Haustiere sind Schwerpunkt dieses Beitrags.

\section{Wandel der Zeckenpopulationen durch Klimaveränderungen}

Zecken (Ixodidae) zählen zu den parasitisch lebenden Milben (Acari). Als Vektoren pathogener Krankheitserreger haben Zecken eine große human- und veteri- närmedizinische Bedeutung. Zecken zählen wie die Insekten zu den wechselwarmen Tieren, deren Entwicklung und Aktivität maßgeblich von den Außentemperaturen abhängig ist. So reicht die Aktivitätsperiode der dreiwirtigen Ixodes-ricinus-Zecke von Temperaturen $\mathrm{ab} 7^{\circ} \mathrm{C}$ aufwärts von Januar bis November. In Deutschland ist Ixodes ricinus von den Küstenregionen bis zu den Alpen vertreten. Das Vorkommen von Ixodes ricinus in Höhen über $2000 \mathrm{~m}$ ist bisher nicht beobachtet worden. Während der Sommermonate ist die Aktivität am höchsten, da dann das Temperaturoptimun zwischen 17 und $20^{\circ} \mathrm{C}$ liegt. Den ersten saisonalen Aktivitätshöhepunkt erreicht Ixodes ricinus im Mai/Juni, gefolgt von einem Herbstgipfel Mitte September bis Anfang November. Ein zweiter wichtiger Faktor für Ixodes ricinus ist die relative Luftfeuchtigkeit, möglichst über 75\% mit optimalen Werten zwischen 80\% und 95\%. Die zunehmend feuchteren Sommer und milderen Winter der letzten Jahre waren bei der Ausbreitung und Zunahme der Populationsdichte der Zecken förderlich [133, 187].

Klimaveränderungen der letzten Jahre mit einem Anstieg der Jahresdurchschnittstemperatur, mildere Winter mit vermehrten Niederschlägen mit hoher Luftfeuchtigkeit im mittel- und nordeuropäischen Raum, ein Überbestand an Wild sowie das Vordringen von Füchsen und Nagern in städtische Bereiche haben insgesamt zu einer Vergrößerung der Zeckenpopulation und Ausbreitung der Zecken in nördliche Bereiche Europas geführt. Der zwischenstaatliche Ausschuß für Klimafragen (Intergovernmental Panel on Climate Change) der Vereinten Nationen und die Weltorganisation für Meteorologie akzeptiert einen mittleren Oberflächentemperaturanstieg der Erde seit 1860 um $0,6^{\circ} \mathrm{C}$. Niederschläge sind im Mittel von 1990 bis 1999 über den Kontinenten außerhalb der Tropen gestiegen und nahmen in den Wüstenregionen von Afrika und Südamerika ab [88]. Unter Beachtung von Rückkopplungseffekten im Kohlenstoffkreislauf wird eine dramatische, weitere Erwär- 
mungsbeschleunigung von den Klimaforschern prognostiziert, die schlimmstenfalls bis Ende dieses Jahrhunderts bis zu $7,7^{\circ} \mathrm{C}$ betragen könnte. So konnte bereits die nördliche Expansion und Zunahme der Zeckendichte von Ixodes ricinus in Schweden von 1980 bis Mitte 1990 vornehmlich auf mildere Wintertemperaturen zurückgeführt werden [100]. Wärme Temperaturen begünstigen die schnellere Entwicklung und Ausbreitung von Zecken und damit auch von Krankheitserregern [12]. Auch die Durchseuchungsrate von Zecken mit pathogenen Erregern hat in Deutschland zugenommen. Klimaveränderungen haben zudem einen Einfluß auf die Verteilung der verschiedenen Zeckenarten. Durch Zecken übertragene Erkrankungen zählen zu den wichtigen neu auftauchenden Infektionskrankheiten in Europa [109]. Verschiedene Indizien unterstützen die Vorstellung, dass sich die geographische und räumliche Verteilung europäischer Zeckenvektoren in den letzten Jahrzehnten signifikant verändert hat $[101,138,139]$.

\section{Dermacentor reticulatus auf dem Vormarsch}

Dermacentor reticulatus zählt wie Ixodes ricinus (Abb.1a) zu den Schildzecken (Ixodidae), ist etwas größer und bewegt sich schneller als der gemeine Holzbock. Vollgesogene Weibchen werden $10 \mathrm{~mm}$ lang. Diese Buntzecke (engl. ornate cow tick) besitzt ein weißlich emailleähnliches Scutum, das vielfarbig ornamentiert ist (Abb. 1b). Ihr Wirtsspektrum umfasst Rind, Pferd, Hund, Schaf, Ziege, Wildwiederkäuer, Fuchs, Dachs, Igel und andere Tiere [133]. In Frankreich zählt Dermacentor reticulatus zum wichtigsten Vektor der Babesiosis canis (Hundemalaria), der 2004 mehrere tausend Hunde zum Opfer fielen. Kürzlich ließen sich bei 222 Hunden aus Berlin und Brandenburg Ixodes ricinus in 60,8\%, Dermacentor reticulatus in $11,2 \%$ und Ixodes hexagonus (Igelzecke) in 4,1\% nachweisen [33]. Obwohl Ixodes ricinus zu der häufigsten Schildzecke in Mitteleuropa und Deutschland zählt, ist der vorwiegend im Mittelmeerraum beheimatete Dermacentor reticulatus auf dem Vormarsch in nördliche Gebiete. Eine Infestation mit Dermacentor reticulatus wurde in einer bundesweiten Studie der Jagdsaison 2004 bei 3,2\% des erlegten Rotwildes festgestellt [33]. Bei 23\% der vom Rotwild isolierten Dermacentor-reticulatus-Zecken wurde mittels PCR die Rickettsienspezies RpA4 identifiziert, die zuerst bei Rhipicephalus-Zecken in Rußland nachgewiesen wurde. Dermacentor reticulatus ist durch Übertragung des Q-Fiebers durch Coxsiella burnetti für den Menschen und durch Übertragung der Babe-
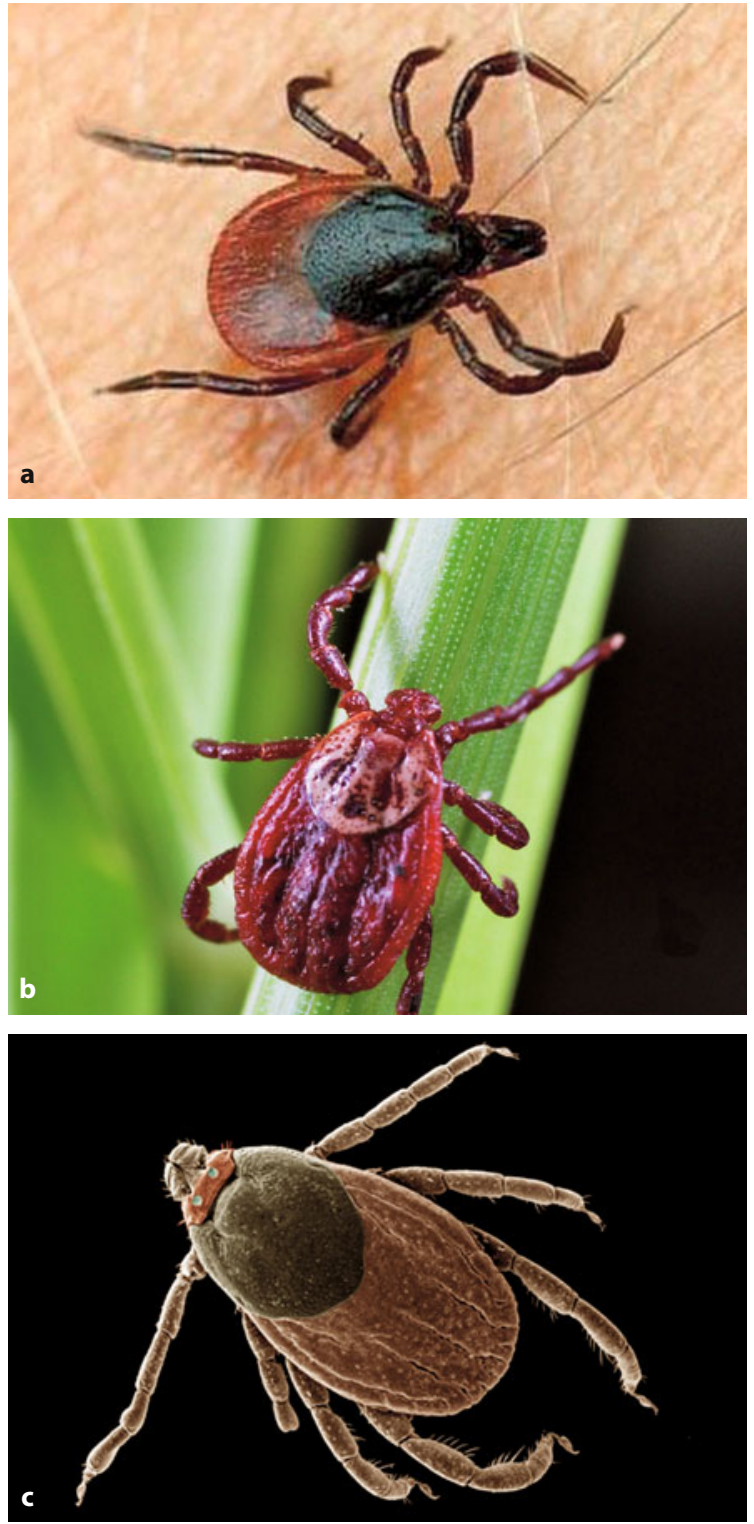

Abb. 1. Morphologische Unterschiede von Ixodes ricinus (gemeiner Holzbock) (a), Dermacentor reticulatus (große Buntzecke) (b) und Rhipicephalus sanguineus (braune Hundezecke) (c)

siose (Babesiosis canis canis) für Hunde gefährlich [82, $107,128]$. Auch in Polen wird das vermehrte Vorkommen von Dermacentor reticulatus beobachtet. Hier konnte im Zeitraum 2003 bis 2004 in 285 untersuchten Dermacentor-reticulatus-Zecken bei 40,7\% Rickettsien-DNA nachgewiesen werden, wobei bei 3,5\% der Zecken Rickettsien der Fleckfiebergruppe beobachtet wurden [162]. Die Rickettsien wiesen eine 98\%ige Homologie zur Rickettsienspezies RpA4 auf, 
die auf dem Territorium der ehemaligen Sowjetunion erstmals beobachtet wurde. Somit rückt die Rickettsienspezies RpA4 der Fleckfiebergruppe näher an Deutschland heran. Dermacentor reticulatus kann zudem auch Borrelien, Rickettsia conorii, den Erreger des Mittelmeerfleckfiebers und das FSME-Virus übertragen [133].

\section{Häufigste Zeckenarten bei Hund und Katze in Mitteleuropa}

An der Zeckenverbreitung in den menschlichen Wohnbereich sind vor allem Haustiere beteiligt. Die Veterinärmediziner stellen heutzutage vermehrt Zeckenbefall bei Hunden als auch zunehmend bei Katzen fest [133]. In Mitteleuropa ist Ixodes ricinus bei Hunden und Freigängerkatzen die häufigste Zeckenart. Bei Hunden wird in Deutschland Dermacentor reticulatus als zweithäufigste Zeckenart beobachtet [33]. Darüber hinaus finden sich bei Hunden je nach Gebiet Rhipicephalus sanguineus (braune Hundezecke) (Abb. 1c), Ixodes hexagonus (Igelzecke), Ixodes canisuga (Hunde- beziehungsweise Fuchszecke) sowie gelegentlich Dermacentor marginatus, Haemaphysalis concinna und Haemaphysalis inermis [133].

\section{Durch Zecken übertragbare Krankheiten}

Die Borreliose hat von den durch Zecken übertragenen Erkrankungen in Mitteleuropa die größte Bedeutung für die Dermatologie [119], wohingegen in den USA neben der Lyme-Borreliose das Rocky Mountains-Fleckfieber durch Übertragung von $R i$ ckettsia rickettsii die häufigste in den USA vorkommende Rickettsiose ist $[107,163]$. Im deutschen und europäischen Raum sind Zecken Überträger des FSME-Virus (Frühsommermeningoenzephalitis), von Babesien (Babesiose), Ehrlichien (Ehrlichiose), verschiedener Rickettsienarten wie Rickettsia conorii (Boutonneuse-Fieber), Rickettsia monacensis (klinisches Bild noch unbekannt), Rickettsia slovaca (TIBOLA), Coxiella burnetti (Q-Fieber), von Franciscella tularensis (Tularämie), dem Eyach-Virus, von Mykoplasmen und Bartonellen wie Bartonella henselae (Katzenkratzkrankheit). Die Übertragung von Hepatitis-C-Virus (HCV) durch Zeckenstich legen zudem zwei Kasuistiken nahe [196].
Borreliose

\section{Aktuelle Daten zur Epidemiologie}

Etwa 5-35\% aller Ixodes ricinus sind mit Borrelien befallen, wobei Adulte bis zu 20\%, Nymphen zu etwa $10 \%$ und Larven bis zu 1\% durchseucht sind [187]. Entsprechend der Datenlage des Robert-Koch-Instituts ist in Deutschland nach einem Zeckenstich in 3-6\% der Betroffenen mit einer Serokonversion und in $0,3-1,4 \%$ mit einer manifesten Erkrankung zu rechnen. Der Stich einer Borrelien-infizierten Zecke führt bei $20-30 \%$ der Gestochenen zur Serokonversion. Nach Schätzungen des Robert-Koch-Instituts treten in Deutschland 60000 Neuerkrankungen von Borreliose auf [187], der Bundesverband Zeckenkrankheiten (BZK) geht gar von einer bundesweiten Inzidenz bis 100000 Neuerkrankungen pro Jahr aus [14]. Das Institut für Medizinische Parasitologie der Universität Bonn untersuchte von März bis Oktober 2003 insgesamt 2518 Ixodes-ricinus-Zecken im Stadtgebiet und in der Umgebung von Bonn [105]. Borrelia burgdorferi sensu lato fanden sich in 17,9\% der untersuchten Zecken, wobei die Infektionsprävalenz von weiblichen Adulten 26,6\%, von männlichen Adulten $12,5 \%$ und von Nymphen 17,3\% betrug [105]. Genospezifischen Untersuchungen zeigten, dass im Raum Bonn an erster Stelle mit 39,5\% Borrelia afzelii, gefolgt von Borrelia garinii (27,9\%), Borrelia burgdorferi sensu stricto $(15,6 \%)$ und Borrelia valaisiana $(8,6 \%)$ und Doppelinfektionen (4,3\%) angetroffen wurden [105] (Abb. 2). Bemerkenswerter Weise fand sich kein signifikanter Unterschied in der Borreliendurchseuchung der Zecken im Vergleich zwischen Stadt- und Stadtrandlage. Ixodes ricinus parasitieren auch auf heimischen Singvögeln und werden von diesen verbreitet. In Reifenstein (Thüringen) wurden von März bis Oktober 2004 von 322 Vögeln (35 Vogelspezies) 141 Ixodes-ricinus-Zecken von 53 Vögeln eingesammelt. Mit Borrelia burgdorferi sensu lato waren $25 \%$ der Ixodes ricinus vorrangig von der Amsel (Turdus merula), der Singdrossel (Turdus philomelos) und vom Dompfaff (Pyrrhula pyrrhula) infiziert [83]. Bei der genotypischen Analyse der Borrelienspezies bei Vögeln isolierter Ixodes ricinus stand Borrelia garinii mit 53\% an erster Stelle, gefolgt von Borrelia valaisiana mit $28 \%$ [83]. Dagegen waren in der Region gesammelte Ixodes ricinus nur zu 15,2\% mit Borrelia burgdorferi sensu lato infiziert. Mit $45 \%$ war Borrelia valaisiana die häufigste Genospezies. Diese Befunde machen deutlich, dass den heimischen Singvögeln eine Bedeutung in der Vermehrung und im Lebenszyklus der Zecken zukommt [83]. 
Abb. 2. Verteilung der Borrelia burgdorferi Genospezies von Ixodes ricinus im Raum Bonn 2003

\section{Genotypen Borrelia burgdorferi- infizierter Ixodes ricinus, Bonn 2003}



\section{Borrelia-burgdorferi-Koinfektionen mit anderen Zeckenerregern}

Die unterschiedlichen klinischen Verläufe einer Dermatoborreliose sind nicht nur auf die unterschiedlichen Genotypen der Borrelien zurückzuführen, sondern sind vermutlich Ausdruck von Koinfektionen mit anderen durch Zeckenstich übertragenen Erregern. Eine Koinfektion von Ixodes-Zecken mit dem gram-negative Leukozyten infizierenden Erreger der humanen granulozytären Ehrlichiose, Anaplasma phagocytophilum, wurde bei bis zu $4 \%$ beobachtet [10]. Im Sommer 2004 wurde in einem bewaldeten Endemiegebiet in Österreich bei 3\% der 131 untersuchten Ixodes-ricinus-Zecken Anaplasma phagocytophilum nachgewiesen [57]. 21\% der Zecken waren positiv auf Borrelia burgdorferi sensu lato. Bei $67 \%$ der Borrelien-positiven Zecken fand sich Borrelia afzelii, bei $19 \%$ Borrelia burgdorferi sensu stricto, bei $11 \%$ Borrelia garinii und bei 3\% Borrelia valaisiana, 0,8\% der Zecken waren mit Borrelia afzelii und Anaplasma phagocytophilum koinfiziert [57].

Eine Koinfektion der Zecken mit Babesien, intraerythrozytär lebenden Protozoen, sollte ebenfalls berücksichtigt werden [119]. Im Nordosten der USA fanden sich bei $2 \%$ der Patienten mit Erythema migrans Koinfektionen mit Babesia microti, einer Nagerbabesie [164]. Die Datenlage zum Vorkommen von Babesien ist in Deutschland nur unzureichend charakterisiert. Hunfeld et al. [72] fanden im RheinMain-Gebiet eine Seroprävalenz von zumindest einem Babesia-Antigen bei 11,5\% zeckenexponierter
Individuen, einschließlich von Patienten mit positiver Borrelienserologie und/oder Erythema migrans im Vergleich zu 1,7\% gesunder Blutspender. Da die Ehrlichiose wie auch die Babesiose eine eigene klinische Symptomatik hervorrufen können, ist bei einer Koinfektion der Zecken mit diesen Erregern mit einer Modulation des klinischen Bildes einer Dermatoborreliose zu rechnen [119]. Die Übertragung einer Borreliose scheint ferner durch eine erworbene Hypersensitivität auf Zeckenspeichelantigene reduziert $\mathrm{zu}$ werden [142, 193]. Burke und Kollegen [15] der Tickborne Infection Study Group der Harvard-Universität konnten jüngst zeigen, dass mehr als drei mit Juckreiz assoziierte Zeckenstiche vor der Übertragung der Lyme-Borreliose schützen. Dieser positive immunologische Effekt einer erworbenen Hypersensitivität gegen Zeckenspeichelantigene eröffnet die Möglichkeit einer Schutzimpfung, die möglicher Weise auch die Transmission eines breiten Spektrums von Zeckenerregern erschwert [15].

\section{Fortschritte in der Borrelienserologie: C6-ELISA}

Die bisher verfügbaren serodiagnostischen Tests der Borreliose erlaubten nicht den Nachweis der drei in Europa relevanten Borreliengenospezies (B. afzelii, B. burgdorferi sensu strictu, B. garinii) mit gleicher Spezifität und Sensititvität. Ein kürzlich näher charakterisiertes Borrelien-Oberflächenlipoprotein, das variable major-protein-like sequence, expressed (VlsE) weist sechs konstante, invariable Domänen auf, die bei allen Borrelienstämmen und Genospezies von 
Borrelia burgdorferi sensu lato gleichermaßen konserviert sind [97-99]. Diese Erkenntnis ermöglichte die Verwendung eines synthetischen C6-Peptids der immunogenen konstanten Domäne des VlsE-Oberflächenproteins und die Entwicklung eines C6-PeptidELISA, der die pathogenen europäischen Genospezies von Borrelia burgdorferi mit gleicher Sensitivität erkennt [4]. Für den Immunetics ${ }^{\circledR}$ C6 Lyme ELISA ${ }^{\text {TM }}$ wird eine Spezifität von $98 \%$ und eine Sensitivität von 97\% bei Tests an US-amerikanischen Patienten mit Lyme Disease angegeben. Der C6-ELISA eignet sich als Universaltest zur Erfassung von Früh- und Spätstadien europäischer Borreliengenospezies und erspart in Zukunft möglicherweise Western-Blot-Bestätigungsreaktionen.

\section{Prävention von Zeckenstichen}

Zur Prävention von Zeckenstichen und Übertragung einer zeckenbedingten Infektion zählt vor allem das Meiden zeckenkontaminierter Haus- und Wildtiere, das Beseitigen von Laub- und Blattabfällen in Gärten und die Exposition zu Zeckenendemiegebieten, insbesondere Wiesen und Feuchtbiotopen [42, 119, 187]. Weisshaar et al. [191] konnten kürzlich bei einer Untersuchung von 506 Kindern von 25 Waldkindergärten im Vergleich zu 1201 Kindern konventioneller Kindergärten in Baden-Württemberg zeigen, dass die Gruppe der Kinder aus Waldkindergärten gegenüber der nicht primär im Freien spielenden Kinder ein 2,8fach erhöhtes Zeckenstichrisiko und ein 4,6fach erhöhtes Borrelioserisiko aufwiesen. Bei Gartenarbeit oder bei Freizeitaktivitäten wie beim Golfen oder Joggen sollten Zeckenrepellentien verwendet werden wie mosquito ${ }^{\circledR}$ Zeckenspray, Viticks cool ${ }^{\circledR}$ oder Au$\tan ^{\circledR}$ [187]. In jedem Fall müssen aber die Schuhe, Hose, Socken und freie Hautpartien an den Unterschenkeln komplett besprüht oder eingecremt werden. Es empfiehlt sich geschlossene Beinkleidung. Permethrin-Zeckenspray, welches in Deutschland nicht zum Aufbringen auf die Haut zugelassen ist, bleibt nach Applikation auf die Kleidung sogar nach mehreren Waschgängen noch aktiv [42] und bietet insbesondere in Kombination mit 30\%igem DEET (N, N-Diethyl-3-methylbenzamid), das auf die exponierte Haut aufgebracht wird, derzeit den besten Schutz zur chemischen Zeckenprophylaxe in Europa $[187,198]$. Da die im Mitteldarm der Zecken vorkommenden Borrelien meist erst nach 24- bis 36stündigem Anhaften der Zecken übertragen werden [8], wird eine sofortige Zeckenentfernung ohne Quetschen des Zeckenabdomens angestrebt [187]. Empfohlen wird das vorsichtige Herausziehen der Zecke unterhalb des Zeckenkopfes unter Zuhilfenahme

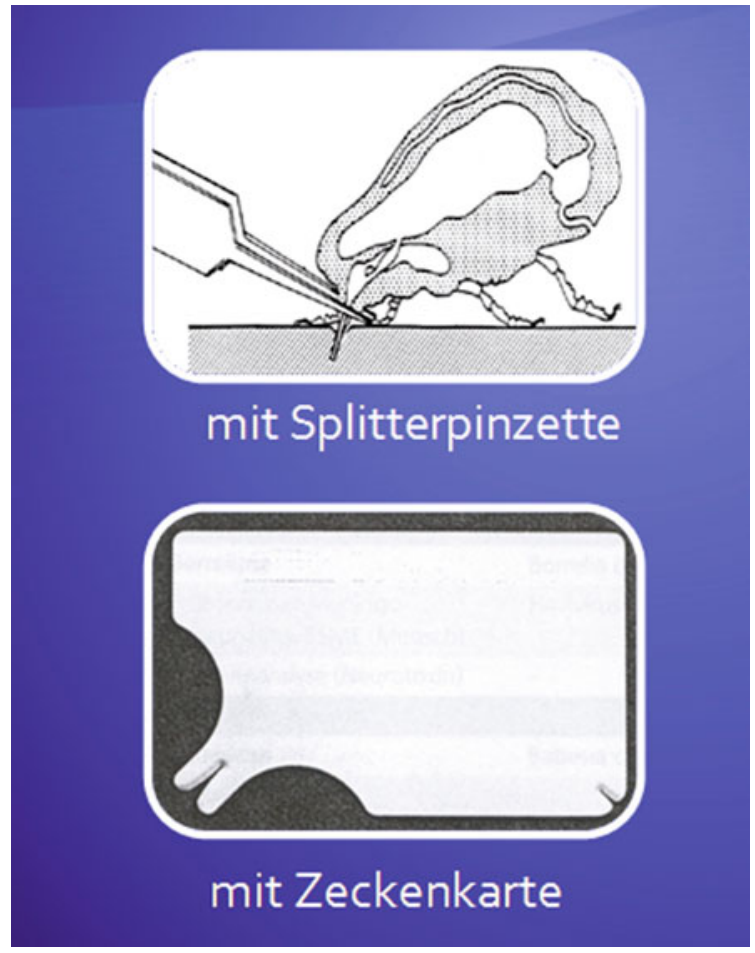

Abb. 3. Zeckenentfernung mittels Splitterpinzette oder Zeckenkarte. Eine Manipulation des Zeckenabdomens läßt sich durch beide Techniken vermeiden

einer Splitterpinzette oder einer neu im Handel befindlichen Zeckenkarte (Wepa Apothekenbedarf) [187]. Diese im Kreditkartenformat angebotene Karte enthält zwei unterschiedlich große Einkerbungen zum parallelen Fassen der Zecke tangential zwischen menschlicher Haut und Zeckenkörper. Mit einer leicht schaukelnden Ziehbewegung wird die Zecke nach ober gezogen und dabei entfernt (Abb. 3).

Als Standardtherapie des Erythema migrans gilt bei Erwachsenen die tägliche Gabe von $2 \times 100 \mathrm{mg}$ Doxyzyklin über zwei bis drei Wochen $[42,107,119]$. Weitere Therapieoptionen sind den aktuellen Standardwerken der Dermatologie zu entnehmen.

\section{Ehrlichiose}

Anaplasma phagocytophilum sind intrazellulär lebende, gram-negative, Leukozyten infizierende Bakterien, die in Phagosomen neutrophiler Granulozyten lokalisiert sind. Sie führen zur humanen granulozytären Ehrlichiose (HGE) [10, 131, 182, 188]. Ein bis vier Wochen nach dem Zeckenstich tritt die HGE mit unspezifischen grippeartigen Symptomen wie Fieber, Rigor, Myalgien, Arthralgien, Kopfschmerzen, Abge- 
schlagenheit und Lymphadenopathie auf [131, 182]. Eine klinische Abgrenzung von einer Borrelieninfektion ist schwierig. Die Verläufe der HGE in Europa scheinen milder und komplikationsärmer zu sein als in den USA, wo auch letale Verläufe, vor allem bei Immunsupprimierten beobachtet wurden [5]. Unspezifische Exantheme wurden bei 1-16\% amerikanischer Patienten beobachtet [5]. Im Routinelabor fallen meist eine Leukopenie, Thrombozytopenie und erhöhte Transaminasen auf. In Wright- oder Giemsagefärbten Blutausstrichen können Anaplasma phagocytophila als Morulae (intragranulozytäre Aggregationen von Anaplasma phagocytophila) nachgewiesen werden [5]. Zur Diagnostik werden meist Immunfluoreszenzantikörpertests eingesetzt [124]. Bei Patienten in verschiedenen Borreliosestadien und zeckenexponierten Individuen in Endemiegebieten fanden sich erhöhte Antikörpertiter gegen Anaplasma phagocytophilum in 4 bis $21 \%$ im Vergleich zu maximal $4 \%$ bei gesunden Blutspendern $[49,119]$. Mittel der Wahl zur Behandlung der HGE ist Doxyzyklin, welches in einer täglichen Dosis von $200 \mathrm{mg}$ mindestens eine Woche eingenommen werden sollte. Glücklicherweise werden Ehrlichien bei der Standardtherapie der Borreliose mit Doxyzyklin miterfasst.

\section{Babesiose}

Die Babesiose ist eine akute fieberhafte Protozoenerkrankung nach Zeckenstich, die durch bisher vier bekannte Spezies (Babesia divergens, Babesia microti, WA1 und MO1) hervorgerufen werden kann. Die Babesien sind intraerythrozytäre Parasiten und führen zu einer Malaria-artigen Erkrankung, allerdings ohne Pigmentbildung. Bei Hunden verläuft die unerkannte Erkrankung häufig tödlich [133]. In Europa ist Babesia divergens der häufigste Erreger, in den USA Babesia microti. Alle Babesienspezies werden durch Ixodes-Arten übertragen. Je nach geographischem Gebiet beträgt die Rate der Koinfektion einer Borreliose mit Babesia zwischen 11 und 23\%. Bei einer Koinfektion muss mit einem schweren Verlauf und längeren Dauer der Borreliose gerechnet werden. Die Babesiose verläuft als ein- bis zweiwöchige grippeartige Erkrankung. Gefährdet sind vor allem Splenektomierte, ältere Patienten und Immunsupprimierte [89, 90]. Unspezifische Exantheme wurden in bis $\mathrm{zu} 11,7 \%$ hospitalisierter amerikanischer Patienten mit Babesiose gefunden [192]. Auf das vermehrte Vorkommen von Petechien und Ekchymosen bei einer Babesiose wird hingewiesen.
Während Krause et al. [90] bei $88 \%$ der Patienten mit Borreliose ein Erythema migrans beobachteten, fanden sich in der Gruppe von Babesia-koinfizierten Borreliosepatienten nur in $62 \%$ ein Erythema migrans. Ein immunmodulierender Effekt einer Babesienkoinfektion auf den Verlauf einer Dermatoborreliose scheint somit möglich. Zur bisher noch nicht standardisierten Labordiagnostik der Babesiose werden Blutausstrich, PCR und Antikörpertests eingesetzt $[89,90,190]$. Im Rhein-Main-Gebiet wurde eine Seroprävalenz in der allgemeinen Bevölkerung von 5,4\% für Babesia microti und 3,6\% für Babesia divergens gefunden [72]. Die Hauptwirte sind allerdings Nager beziehungsweise Rinder.

Die Babesiose des Hundes wird durch Babesia canis canis, die großen Babesien des Hundes, meist durch Dermacentor reticulatus und Rhipicephalus sanguineus übertragen [133]. Ein vermehrtes Vorkommen von Babesiosen des Hundes wurde in letzter Zeit im Saarland, Baden-Württemberg und Sachsen beobachtet. Die Erkrankung führt bei unbehandelten Hunden durch Hämolyse und disseminierte intravasale Gerinnung oft zum Tode. Die sich in Deutschland ausdehnende Babesiose des Hundes ist ein Indikator für die weitere Ausbreitung von Demacentor reticulatus.

Zur Babesiosebehandlung des Menschen wird bei stärkerer Symptomatik oral Chinin in Salzform täglich $3 \times 650 \mathrm{mg}$ für 7 Tage und Clindamyzin täglich $3 \times 600 \mathrm{mg}$ über 7 Tage eingesetzt. Gleiche Wirksamkeit und geringere Nebenwirkungen hat die orale Kombinationstherapie von Atovaquon täglich $2 \times 750 \mathrm{mg} 7$ bis 10 Tage und Azithromyzin täglich $600 \mathrm{mg} 7$ bis 10 Tage $[89,90]$. Ein gleichzeitiger Blutaustausch unterstützt nach Erfahrungen des französischen Militärs die leider ungenügende Chemotherapie.

\section{Q-Fieber}

Q-Fieber wird durch den obligat intrazellulären, pleomorphen, gram-negativen Coccobacillus Coxiella burnetii hervorgerufen, der eine beträchtliche Homologie zu Legionella pneumophila aufweist [185]. Die Vermehrung der Bakterien erfolgt in Phagolysosomen [185]. Obwohl verschiedene Zeckenarten als Reservoir von Coxiella burnetii gelten [195], wird der Erreger meist nicht durch Zeckenstich übertragen [108], wohl aber durch Inhalation oder Einreiben von Zeckenfäzes, in denen der Erreger konzentriert ist. Durch beruflichen Kontakt zu zeckenkontaminierten Fellen oder Wolle ist eine Infektion des Menschen 
möglich. Rinder, Schafe und Ziegen sind die häufigsten Infektionsquellen des Menschen, meist jedoch durch Inhalation infektiöser Aerosole durch kontaminierte Tiere, deren Ausscheidungen und vor allem durch Kontakt mit hochinfektiösen Geburtsrückständen. In Deutschland kam es zu Ausbrüchen von Q-Fieber in Hessen in der Nähe infizierter Schafsherden sowie bei Besuch eines Bauernmarktes in Westfalen durch Kontakt mit einem infizierten Lamm. In Deutschland spielt die Schafszecke (Dermacentor maginatus) als Überträger von Coxiella burnetii von Tier zu Tier eine bedeutende Rolle [132].

Die akute Phase des Q-Fiebers weist eine grippeartige Symptomatik mit unterschiedlich schwerer Pneumonie und Hepatitis auf $[82,128]$. Hepatomegalie und erhöhte Transaminasen finden sich häufig. Exantheme (makulopapulös oder purpurisch) werden in 5-20\% der Fälle beobachtet $[1,175]$. Kürzlich wurde über ein unter dem klinischen Bild eines systemischen Lupus erythematodes verlaufendes Q-Fieber mit Fieber, Exanthem, Perikarditis und hohen Titern von ANA, anti-Sm und anti-RNP und hohen Antikörpertitern von Coxiella burnetii berichtet, das nach Verabreichung von Minozyklin schnell abheilte [126]. Eine Endokarditis tritt als Komplikation bei chronischer Q-Fieber-Infektion auf. In Marseille konnte bei 15\% der Patienten mit Endokarditis Coxiella burnetii nachgewiesen werden [106]. Endokarditis gefährdet sind vor allem Patienten mit vorbestehenden Vitien und Immunsupprimierte. Eine Langzeitfolge des Q-Fiebers scheint auch das chronische Müdigkeitssyndrom zu sein [128]. Coxiella burnetii gefährdet ferner die Schwangerschaft. Es wurden vermehrt Aborte und Frühgeburten verzeichnet [128].

Als diagnostische Standardmethode gilt derzeit die indirekte Immunfluoreszenz [53]. Als Mittel der Wahl zur Behandlung der akuten Erkrankungsphase wird Doxyzyklin $2 \times 100 \mathrm{mg}$ über 14 Tage empfohlen [40]. In Deutschland sind Q-Fieber-Infektionen bei Mensch und Tier meldepflichtig.

Durch Zecken übertragene Rickettsiosen

im europäischen Raum

Zahlreiche Rickettsienspezies werden weltweit in Zecken gefunden. Pathogene Rickettsien werden in drei Gruppen eingeteilt: Typhusgruppe, Fleckfiebergruppe und Rickettsia tsutsugamushi. In den USA ist das Rocky Mountains Spotted Fever (Erreger Rickettsia rickettsii, Vektoren: Dermacentor andersoni und Dermacentor variabilis) von größter epidemiologischer und klinischer Bedeutung [25]. In Europa stehen Rickettsieninfektionen der Fleckfiebergruppe im Vordergrund.

\section{Europäische Rickettsiosen der Fleckfiebergruppe}

Rickettsien sind pleomorphe, obligat intrazelluläre gram-negative Bakterien, die sich dem Leben im Darmepithel von Arthopoden (Zecken, Milben, Läusen, Flöhen) gut angepasst haben und sich im Zytoplasma infizierter Zellen vermehren. Die Erreger werden durch Zeckenstich oder Zeckenfäzes auf den Menschen übertragen. Viele Rickettsien haben toxische und hämolytische Eigenschaften einschließlich der Bildung endotoxischer Polysaccharide. Bevorzugt werden Endothelzellen befallen, was zu purpurischen Exanthemen, Thrombozytopenie und Gerinnungsstörungen führt [189]. Die Inkubationszeit der europäischen Rickettsien der Fleckfiebergruppe beträgt im Mittel 5 bis 7 Tage. Das klinische Bild ist gekennzeichnet von Fieber, Schüttelfrost, Kopfschmerzen, allgemeinem Krankheitsgefühl, Benommenheit, Entwicklung eines meist nach 4 bis 7 Fiebertagen auftretenden makulopapulösen Exanthems, das später in eine purpurische Komponente übergeht. An der Stichstelle besteht häufig ein bis $1 \mathrm{~cm}$ großes hämorrhagisch-nekrotisches Ulkus mit schwärzlichem Schorf (franz. tâche noire). Bis in die 90iger Jahre ging man in Europa davon aus, dass das mediterrane Zeckenstichfieber, hervorgerufen durch Rickettsia conorii und übertragen von der in Südeuropa verbreiteten Art, Rhipicephalus sanguineus (braune Hundezecke), die einzige in Europa auftretende Erkrankung der Fleckfiebergruppe sei. In den letzten Jahren wurden in Europa jedoch zunehmend weitere humanpathogene Rickettsienspezies der Fleckfiebergruppe identifiziert (Tabelle 1) [24, 54, 92, 93, 102, 161]. Drei der neu endeckten Rickettsien sind auch in Deutschland nachgewiesen worden: Rickettsia helvetica (Vektoren: Ixodes ricinus, Ixodes persulcatus), die im englischen Garten von München entdeckte Rickettsia monacensis (Vektor: Ixodes ricinus) und Rickettsia slovaca (Vektoren: Dermacentor marginatus und Dermacentor reticulatus), den Erreger der Tibola (tick-borne lymphadenopathy) [92, 93]. Bei einer kürzlich durchgeführten Untersuchung zur Rickettsiendurchseuchung der drei anthropophilen Zecken in Ungarn fanden sich Rickettsien der Fleckfiebergruppe in 1,0\% bei Haemaphysalis concinna, in $2,7 \%$ bei Ixodes ricinus und in $26,8 \%$ bei Dermacentor reticulatus [161]. Diese Befunde verdeutlichen, dass Dermacentor reticulatus auch bei der Transmission von Rickettsien eine bedeutende Rolle spielt. Es wurde auch ein neuer Rickettsiengenotyp der Fleckfiebergruppe identifiziert 
Tabelle 1. Geographische Verteilung von Rickettsien der Fleckfiebergruppe und Vektoren in Europa*

\begin{tabular}{|c|c|c|c|c|}
\hline Rickettsien-Spezies & $\begin{array}{l}\text { Häufigster } \\
\text { Zeckenvektor }\end{array}$ & $\begin{array}{l}\text { Geographische } \\
\text { Verteilung } \\
\text { des Vektors }\end{array}$ & $\begin{array}{l}\text { Infektion } \\
\text { des Vektors (\%) }\end{array}$ & Länder \\
\hline Rickettsia helvetica & Ixodes ricinus, I. persulcatus & Gesamteuropa & $1-16$ & $\begin{array}{l}\text { B, Dä, F, D, U, I, P, } \\
\text { SI, S, Sw, Sch }\end{array}$ \\
\hline Rickettsia monacensis & Ixodes ricinus & Gesamteuropa & 1 & $\mathrm{~B}, \mathrm{D}, \mathrm{U}, \mathrm{I}, \mathrm{SI}, \mathrm{S}$ \\
\hline Rickettsia slovaca & $\begin{array}{l}\text { Dermacentor marginatus, } \\
\text { D. reticulatus }\end{array}$ & Gesamteuropa & $1-100$ & $\begin{array}{l}\text { Ö, B, K, F, D, U, P, R, } \\
\text { SI, S, Sch, Uk }\end{array}$ \\
\hline R. sp. DnS14/RpA4 & Dermacentor & Gesamteuropa & $1-100$ & $F, U, R, S$ \\
\hline $\begin{array}{l}\text { Candidatus Rickettsia } \\
\text { kotlanii }\end{array}$ & Haemaphysalis concinna & Zentral- und Osteuropa & 1 & $\mathrm{U}$ \\
\hline $\begin{array}{l}\text { Rickettsia sibirica subsp. } \\
\text { mongolotimonae }\end{array}$ & Hyalomma truncatum & Südeuropa & unbekannt & $\mathrm{F}, \mathrm{G}$ \\
\hline Rickettsia aeschlimannii & Hyalomma marginatum & Südeuropa & $2-65$ & $K, F, G, I, P, S$ \\
\hline $\begin{array}{l}\text { Rickettsia conorii } \\
\text { (subspp. conorii caspia } \\
\text { und israelensis) }\end{array}$ & Rhipicephalus sanguineus & Südeuropa & $5-12$ & $\begin{array}{l}\text { Al, B, K, F, G, I, P, S, } \\
\text { Sch, T, Uk }\end{array}$ \\
\hline Rickettsia rhipicephali & Rhipicephalus sanguineus & Südeuropa & $1-6$ & $\mathrm{~F}, \mathrm{~K}, \mathrm{G}, \mathrm{P}, \mathrm{S}$ \\
\hline Rickettsia massiliae & Rhipicephalus & Südeuropa & $1-11$ & $F, G, I, P, S, S c h$ \\
\hline
\end{tabular}

* Modifiziert nach [161]. B = Bulgarien, Dä = Dänemark, F = Frankreich, D = Deutschland, U= Ungarn, I = Italien, P= Portugal, $\mathrm{SI}=$ Slovenien, $\mathrm{S}=$ Spanien; $\mathrm{Sw}=\mathrm{Sch}$ weden, $\mathrm{Sch}=\mathrm{Schweiz}, \mathrm{O}=$ Österreich, $\mathrm{K}=$ Kroatien, $\mathrm{R}=$ Russland, Uk = Ukraine, G = Griechenland, $\mathrm{Al}=$ Albanien, $\mathrm{T}=$ Türkei.

mit der vorläufigen Bezeichnung Candidatus Rickettsia kotlanii [161]. Das klinische Bild der Infektion mit Rickettsia helvetica ist noch nicht endgültig charakterisiert. Bekannt ist der Tod zweier Patienten an einer Perimyokarditis als auch Verläufe mit prolongiertem Fieber, Kopfschmerzen, Myalgien und Schwäche [55, 125, 161]. Zudem wurde auch über lymphangitisassoziierte Rickettsiosen durch Rickettsia sibirica mongolotimonae berichtet [56].

Serologische Untersuchungen mittels Immunfluoreszenztests, Immunoblot und PCR-Methoden zur Erregerbestimmung sind in mikrobiologischen Speziallabors möglich [94].

Die Therapie der Rickettsiosen erfolgt frühzeitig, schon bei klinischem Verdacht, durch Gabe von Doxyzyklin in einer täglichen Dosierung von $2 \times 100 \mathrm{mg}$ über mindestens 7-10 Tage und drei Tage über die Entfieberung hinaus. Bei schweren Verläufen mit ZNS-Beteiligung ist Chloramphenicol bei Beachtung der Nebenwirkungen einsetzbar [25].

\section{TIBOLA}

Lakos in Ungarn [92] und Raoult et al. in Frankreich [140] gelang es Rickettsia slovaca als Erreger von TIBOLA (tick-borne lymphadenopathy) zu identifizieren. TIBOLA ist charakterisiert durch vergrößerte, manchmal schmerzhafte Lymphknotenschwellungen meist okzipital oder hinter dem Musculus sternocleidomastoideus [93]. In 96\% der Fälle fand sich die Zeckenstichstelle am Kapillitium. Diese entwickelt sich von einer entzündlichen Papel oder Vesikel in eine charakteristische nekrotische Papel (Eschar) mit gerötetem Randsaum (82\%). An Allgemeinsymptomen wurden insbesondere leichtes Fieber, Müdigkeit, Abgeschlagenheit, Schwitzen, Myalgien, Arthralgien und Appetitverlust beobachtet [93]. Betroffen sind vorwiegend Kinder im Alter unter 10 Jahren (63\% der Patienten). Als Vektor wurden Dermacentor-Zecken beschrieben, in zwei Fällen insbesondere Dermacentor marginatus identifiziert. Die ersten Symptome traten 9 Tage nach dem Zeckenstich auf. Gewöhnlich fanden sich drei große Lymphnoten von $1 \mathrm{~cm}$ bis $5 \mathrm{~cm}$ im Durchmesser. Bei 15\% der Patienten trat einige Tage nach dem Zeckenstich im Bereich der geröteten und geschwollenen 3 bis $5 \mathrm{~cm}$ großen Lokalreaktion an der Stichstelle eine honigartige Sekretion auf [93]. Noch Monate nach dem Zeckenstich fanden sich bei 39,5\% der Patienten umschriebene, rundliche Alopezieherde, die einer Alopecia areata ähnelten [93]. Der Nachweis von Rickettsia slovaca gelang am besten (77\%) durch PCR von Lymphknoten- und Hautbiopsaten. Die Behandlung mit Doxyzyklin hatte den besten therapeutischen Effekt und verkürzte signifikant den Verlauf des Krankheitsbildes [73, 74, 93]. Auf- 
grund des zunehmenden Ferntourismus sollte auch das Afrikanische Zeckenstichfieber (Erreger: Rickettsia africae; Vektor: Amblyomma-Spezies), der Queensland-Zeckentyphus (Rickettsia australis) und der sibirische Zeckentyphus (Rickettsia sibirica) erwähnt werden.

Um die weitere Charakterisierung neuer zeckenbedingter Erkrankungen in Europa voranzutreiben, ist es wünschenswert, wenn Hautärzte in der Lage wären, mitgebachte Zecken zu identifizieren, in flüssigem Stickstoff aufzubewahren, eine Serum- und Plasmaprobe sowie eine Biopsie aus der nekrotischen Zeckenstichstelle zu entnehmen. Das eingefrorene Material sollte dann an ein Speziallabor zur weiteren serologischen und molekularbiologischen Diagnostik weitergeleitet werden.

\section{Katzenkratzkrankheit}

Von den 20 verschiedenen Bartonellaspezies gelten acht als humanpathogen. Bekannt ist vor allem die Übertragung von Bartonellen durch Flöhe. In den USA, Italien und den Niederlanden wurde Bartonella henselae, ein gramnegatives, pleomorphes Stäbchen, der Erreger der Katzenkratzkrankheit, jetzt auch in Ixodes-ricinus-Zecken nachgewiesen [150]. Zecken haben somit wie auch Flöhe das Potential zur Übertragung der Katzenkratzkrankheit. An der Inokulationsstelle entwickelt sich eine Papel, auf die eine regionale Lymphknotenschwellung folgt. Die Behandlung erfolgt symptomatisch, bei stärkerer Symptomatik durch Gabe von Azithromycin.

\section{Tularämie}

Die Tularämie (Hasenpest) wird durch den aeroben, gram-negativen Coccobazillus Francisella tularensis hervorgerufen. Der Erreger wird als potentielle Biowaffe angesehen. Die Übertragung erfolgt durch Kontakt zu erkrankten Tieren, kann aber auch durch Zecken, insbesondere durch Zeckenfäzes auf den Menschen übertragen werden [47]. In Europa gilt Dermacentor marginatus als wichtigster Vektor [129]. Die zeckeninduzierte Tularämie tritt meist zwischen Mai und September auf, während die durch Tiere übertragene Form vor allem im Winter beobachtet wird. Der virulentere Stamm Typ A hat unbehandelt eine Mortalität von $5 \%$ bis $7 \%$. Eine Infektion mit Typ B kann milder und symptomarm verlaufen. Der klinische Typ der zeckenassoziieren Tularämie ist meist die ulzeroglanduläre Form und repräsentiert 45-88\% der Fälle
$[23,78,79]$. Klinische Symptome sind ein schmerzhaftes Ulkus, regionale Lymphadenopathie, Lymphadenitis oder noduläre Lymphangitis. Die Lymphknoten können fluktuieren und einschmelzen.

Die Primärläsion entsteht meist nach einer zweibis fünftägigen Inkubationszeit. Die primär erythematöse, schmerzhafte Papel vergrößert sich auf $0,25 \mathrm{~cm}$ bis $4,0 \mathrm{~cm}$ und ulzeriert unter dem Bild eines ausgestanzten Ulkus mit einer grau-rötlichen bis fleischroten, nekrotischen Basis. Durch systemische Ausbreitung der Erreger treten sekundäre Eruptionen (meist papulöse Tularämide) in 8-20\% der Fälle auf. Zweithäufigste Hautmanifestation ist das Erythema nodosum in 1-13\% der Fälle. Auch Erythema multiforme wurde in 2\% der Fälle beobachtet [2].

Die Diagnose erfolgt primär aufgrund des klinischen Befundes und der Anamnese (Tierkontakt, Zeckenbefall) [13, 47]. Der kulturelle Erregernachweis wird aus Ulkus-, Lymphknoten- und Blutproben veranlasst. Als serologische Bestätigung können Immunfluoreszenzmarkierung und Agglutinationstests mit einem Titer $>1: 160$ herangezogen werden.

Die Behandlung erfolgt mit Streptomyzin i.m. in einer täglichen Dosierung von 15-20 mg/Kg KG abhängig vom Schweregrad der Symptome über 7 bis 14 Tage [47]. Alternativ können Gentamicin (3-5 mg/ $\mathrm{kg}$ KG täglich parenteral für 10-14 Tage) oder Doxycyklin $(2 \times 100 \mathrm{mg}$ täglich für 14 bis 21 Tage $)$ oder Ciprofloxacin $(2 \times 500 \mathrm{mg} /$ Tag über 10 bis 14 Tage $)$ eingesetzt werden $[2,44,47]$.

\section{Durch Zecken übertragene Viruserkrankungen in Europa}

Verschiedene virusbedingte Erkrankungen, die durch Zecken übertragen werden, sind auch für den Hautarzt von Bedeutung. Diese Viren gehören den Genera Flavivirus, Nairovirus und Coltivirus an und führen zu mehr oder weniger schweren neurologischen Erkrankungen, hämorrhagischen Hautveränderungen und Fieber [29]( Tabelle 2).

\section{Zeckenbedingte Enzephalitis: \\ Frühsommermeningoenzephalitis}

Die zeckenbedingte virale Enzephalitis wird durch drei Subtypen des TBE-Virus (Tick-borne encephalitis virus) übertragen. Der bei uns im Vordergrund stehende europäische Subtyp - in der deutschsprachigen Literatur als FSME-Virus besser bekannt wird durch Ixodes ricinus übertragen und verursacht die Frühsommermeningoenzephalitis. Die Prävalenz des Virusbefalls von Zecken wird in Europa mit $0,5-5 \%$ angegeben $[167,168]$. Die Virusübertragung 
Tabelle 2. Durch Zecken übertragene Viruserkrankungen in Europa

\begin{tabular}{|c|c|c|c|}
\hline Genus & Virus & Häufigster Zeckenvektor & Geographisches Vorkommen \\
\hline \multirow[t]{7}{*}{ Flavivirus } & Tick-borne encephalitis virus TBEV & & \\
\hline & Zentraleuropäische Variante FSME & Ixodes ricinus & Zentraleuropa \\
\hline & Sibirische Variante RSSE & $\begin{array}{l}\text { Ixodes persulcatus } \\
\text { Haemaphysalis concinna }\end{array}$ & Russland \\
\hline & Fernöstliche Variante & Ixodes persulcatus & Sibirien, Ural \\
\hline & $\begin{array}{l}\text { Omsk hämorrhagisches } \\
\text { Fieber-Virus }\end{array}$ & $\begin{array}{l}\text { Dermacentor reticulatus } \\
\text { Dermacentor marginatus }\end{array}$ & Omsk, Westsibirien \\
\hline & Powassan-Virus & $\begin{array}{l}\text { Ixodes persulcatus } \\
\text { Haemaphysalis sp. }\end{array}$ & Russland \\
\hline & Louping ill-Virus & Ixodes ricinus & $\begin{array}{l}\text { England, Spanien, Türkei, } \\
\text { Griechenland }\end{array}$ \\
\hline Nairovirus & $\begin{array}{l}\text { Krim-Kongo-hämorrhagisches } \\
\text { Fieber-Virus }\end{array}$ & Hyalomma-sp. & $\begin{array}{l}\text { Afrika, mittlerer Osten, Zentral- } \\
\text { und SW-Asien, Südrussland, } \\
\text { Bulgarien, Griechenland, Kosovo, } \\
\text { Albanien, Türkei }\end{array}$ \\
\hline Coltivirus & Eyach-Virus & $\begin{array}{l}\text { Ixodes ricinus } \\
\text { Ixodes ventalloi }\end{array}$ & $\begin{array}{l}\text { Eyach (Neckar) Deutschland, } \\
\text { Frankreich, Tschechien, Slowakei }\end{array}$ \\
\hline
\end{tabular}

kann bereits unmittelbar nach dem Zeckenstich erfolgen, da das Virus in der Speicheldrüse der Zecke lokalisiert ist. Eine deutliche Zunahme der Verbreitung von FSME-Erkrankungen ist in Deutschland zu beobachten. In 2005 ist die Inzidenz mit 427 neuen FSME-Fällen auf ein bisher nicht erreichtes Niveau gestiegen [187]. Eine weitere Ausbreitung der Endemiegebiete ist $\mathrm{zu}$ beobachten. Neben den altbekannten Endemiegebieten in Bayern und BadenWürttemberg sind neue FSME-Erkrankungen in Hessen, Rheinland-Pfalz und Thüringen hinzugekommen. Informationen über die aktuelle epidemiologische Lage liefert das Robert-Koch-Institut (www.rki.de). In den letzten 5 Jahren hat sich FSME in Deutschland um 65\% ausgebreitet. In Westeuropa treten jährlich etwa 3000 neue Erkrankungen auf. Die allgemeine Inzidenz wird mit $<4$ Fälle pro 100000 Einwohner angegeben. Eine Verbindung zwischen Klimaveränderung, Änderungen der Vektorpopulation und der Enzephalitis-Inzidenz wird vermutet $[100,101]$.

Nach einer Inkubationszeit von 7 bis 14 Tagen beginnt die Erkrankung mit fieberhafter, grippeähnlicher Symptomatik und verläuft nach einem meist achttägigen symptomfreien Intervall bei $74-87 \%$ der Patienten biphasisch mit Auftreten erneuter Symptome und Entwicklung einer Meningoenzephalitis bei $20-30 \%$ der Infizierten [62]. Bei weniger als 1\% der Erkrankten in Europa verläuft die Erkrankung tödlich. Zur serologischen Diagnostik stehen Anti- körpernachweisverfahren mittels ELISA aus Serum oder Liquor zur Verfügung [71]. Die Therapie erfolgt symptomatisch. Seit 2001 besteht in Deutschland Meldepflicht.

Zur Immunprophylaxe wird für Bewohner und Reisende in Endemiegebiete eine Impfung empfohlen. Zwei hochwirksame Impfstoffe mit formaldehydinaktivierten europäischen TBEV-Subtypen (FSMEIMMUN $^{\circledR}$, Baxter Vaccine AG, Wien) sowie Encepur $^{\circledR}$ (Novartis, Marburg) stehen auch in einer halbierten Kinderdosierung (FSME-IMMUN junior ${ }^{\circledR}$ und Encepur ${ }^{\circledR}$ K) zur Verfügung $[6,29,187]$. Die Immunisierung schützt auch vor dem sibirischen und fernöstlichen Subtyp des TBEV [66].

Der sibirische Subtyp des TBEV führt häufiger zu chronischen Verläufen, der mit einer Mortalitätsrate von 5-35\% gefürchtete Fernost-Subtyp ruft stärkere enzephalitische Symptomen hervor [29]. Der fernöstliche und sibirische Subtyp des TBEV wurde kürzlich in Europa (Lettland) isoliert [104, 168]. Infizierte Ixodes persulcatus wurden in Finnland nachgewiesen und werden vermutlich durch Zugvögel verbreitet [187].

\section{Hämorhagisches Omsk-Fieber}

Die Endemiegebiete des Hämorrhagischen OmskFiebers (OHF), hervorgerufen durch das OHFVirus, ein Flavivirus der Familie der Flaviviridiae, befinden sich in Westsibirien. OHF wird durch Zeckenstich von Dermacentor reticulatus und Der- 
macentor marginatus übertragen. Die fieberhafte Erkrankung verläuft meist biphasisch und führt an der Haut zu Petechien und Ekchymosen. Gastrointestinale Blutungen und Hämorrhagien komplizieren den Verlauf. Die Mortalitätsrate liegt zwischen 0,5$3 \%$ [29].

\section{Powassan-Virus-Infektion}

Das Powassan-Virus gehört ebenfalls zum Genus Flavivirus. Bei Infektionen in Rußland erfolgte die Virusübertragung durch Ixodes persulcatus und Haemaphysalis-Zecken. Die Erkrankung führt zu Fieber, Kopfschmerzen, retrobulbären Schmerzen und neurologischen Störungen [29].

\section{Louping-Ill-Virus}

Dieses Flavivirus ist der Hauptverursacher der viralen Enzephalitis bei Schafen. Das Louping-Ill-Virus kann durch Ixodes ricinus übertragen werden. Menschen erkranken meist bei beruflichem Kontakt zu befallenen Tieren. Die Erkrankung verläuft meist biphasisch mit einer enzephalitischen Beteiligung in 50\% der Infizierten. Es können petechiale Hautveränderungen auftreten [29].

\section{Hämorrhagisches Krim-Kongo-Fieber}

Das hämorrhagsiche Krim-Kongo-Fieber-Virus zählt zum Genus Nairovirus der Familie der Bunyaviridae. Es wird durch Hyalomma-Zecken übertragen. Seine Verbreitung erstreckt sich über weite Teile Afrikas, des Mittleren Ostens, Zentral-und Südwestasiens, südliche Provinzen Rußlands, Bulgarien, Griechenland, Kosovo, und Albanien [29]. Letztlich wurde auch über einen Ausbruch mit mindestens 12 Toten in Zentralanatolien (Provinz Yozgat), an der türkischen Schwarzmeerküste und aus dem südtürkischen Mersin berichtet. Im Rahmen der Infektion kann sich eine disseminierte intravasale Gerinnung entwickeln. Meist gehen Petechien ausgedehnteren Hämorrhagien voraus. Großflächige Ekchymosen können in den Intertrigines auftreten. Die durchschnittliche Mortalitätsrate wird mit 30\% angegeben [29].

\section{Eyach-Virus}

Ein dem Colorado-Zeckenfieber-Virus verwandtes Coltivirus aus der Familie der Reoviridae wurde 1976 erstmals im schwäbischen Ort Eyach entdeckt [64]. Es wird durch Ixodes ricinus übertragen. Das Virus wurde in Baden-Württemberg wiederentdeckt und auch in Frankreich und Tschechien isoliert. Bei Patienten mit serologischem Nachweis des Eyach-Virus in Tschechien fanden sich klinisch Fälle mit Enzephalitis und Polyradikuloneuritis [29]. Das Virus wurde 2003 in Baden-Würtemberg erneut isoliert [29]. Serologische Untersuchungen des Hauptwirtes des EyachVirus (europäischer Hase, Lepus europaeus) waren in Schleswig-Holstein und Nordrhein-Westfalen negativ [36]. Das Eyach-Virus ist somit nicht über ganz Deutschland verteilt.

\section{Allergische Lokalreaktionen und Anaphylaxie durch Stich der Taubenzecke}

Die europäische Taubenzecke, Argas reflexus, (Abb. 4) ist ein typischer Vertreter der Lederzecken. Bevorzugte Wirte sind Tauben, Hühner oder Enten. Der Mensch wird als Fehlwirt befallen. Der Stich der Taubenzecke kann lokale und schwere systemische anaphylaktische Reaktionen auslösen. Durch die Zunahme domestizierter Tauben in Süd- und Mitteleuropa ist die Sensibilisierungsgefahr für den Menschen gestiegen. Atopiker scheinen bevorzugt sensibilisiert zu werden. Schwere allergische Reaktionen nach Stichen von Argas reflexus wurden in Deutschland und im europäischen Ausland beobachtet [26, 32, 84, 117, 137, 177]. Da Argas reflexus nachtaktiv ist, können Sensibilisierte durch anaphylaktische Reaktionen im Schlaf überrascht werden. Das Hauptallergen von Argas reflexus (Arg r 1) ist ein im Speichel der Zecke enthaltenes Protein [70, 158]. Kleine-Tebbe et al. [84] untersuchten 148 Personen, die von Taubenzecken gestochen worden sind. Von diesen hatten $99 \%$ allergische Lokalreaktionen, $8 \%$ jedoch anaphylaktische Reaktionen. In $82 \%$ untersuchter Seren fand sich im Immunoblot ein IgE-bindendes Protein mit einem Molekulargewicht von $22 \mathrm{kD}$, bei dem es sich vermutlich um das Majorallergen von Argas reflexus handelt [84].

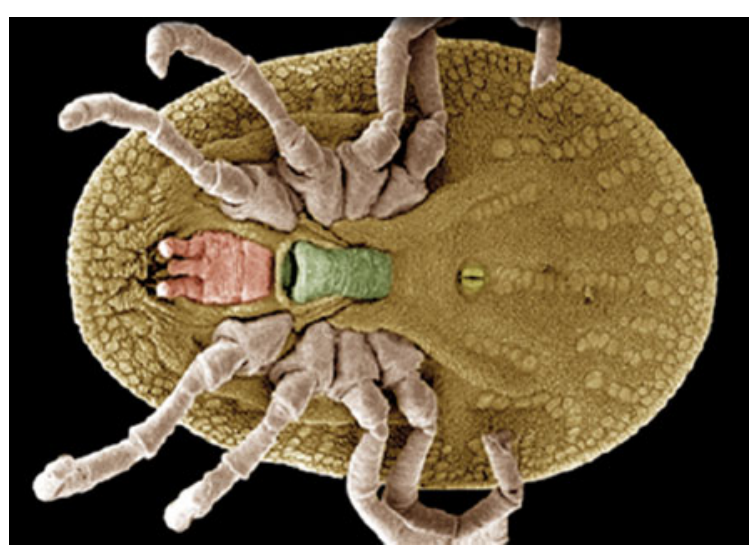

Abb. 4. Argas reflexus (Taubenzecke), entnommen mit freundlicher Genehmigung aus [114] 


\section{Ektoparasitosen und Vektor-übertragene Infektionen bei Obdachlosen}

Obdachlose sind Ektoparasiten und arthropodenbedingten Erkrankungen in einem hohen Maße ausgesetzt und stellen eine epidemiologisch bedeutsame Risikogruppe für die Verbreitung von Zoonosen dar. In einer vierjährigen Studie an 930 Obdachlosen in Marseille fanden sich bei 22\% Lausinfestationen mit Hypereosinophilie, bei 3\% Skabies und bei 5,3\% positive Blutkulturen von Bartonella quintana, dem Erreger des Fünftagefiebers, Auslöser bakterieller Endokarditis, bazillärer Angiomatose und Verursacher unklaren Fiebers bei HIV-Infizierten $[13,87]$. Darüber hinaus wurden bei Obdachlosen erhöhte Seroprävalenzen von Borrelia recurrentis (Rückfallfieber), Rickettsia conorii (mediterranes Fleckfieber) und Rickettsia prowazekii (endemischer Typhus) beobachtet [13]. Die hohen Prävalenzen der Lausinfestationen und Zeckenexpositionen bei Obdachlosen bergen die Gefahr des Wiederauftretens ernster arthropodenvermittelter Zoonosen $[13,129,165]$. Obdachlose werden häufig auch von Larven (Maden) von Schmeißfliegen (Gattungen Sarcophaga, Calliphora, Lucilia) zum Beispiel an Ohren oder Nase befallen, die mechanisch entfernt werden müssen.

\section{Pedikulosen}

\section{Pediculosis capitis}

Die Infestation des Menschen mit der Kopflaus, Pediculus humanus capitis, nimmt in den letzten Jahren weiter zu und betrifft alle sozioökonomischen Schichten der Gesellschaft $[85,143]$. Ein sprunghafter Anstieg des Bedarfs an Läusemitteln nach den Sommerferien spricht für einen Zusammenhang mit internationaler Reiseaktivität. Die Kopflausinfektion betrifft häufig Kindergarten-und Schulkinder, vor allem Mädchen mitlangen Haaren. Der Hauptübertragungsmechanismus der Kopflausinfestation ist der Kopfzu-Kopf-Kontakt. Eine Übertragung durch kontaminierte Gegenstände spielt im Vergleich nur eine geringe Rolle [169]. Optimale Bedingungen für den Laustransfer bestehen, wenn nicht infizierte lange Haare parallel zum infestierten Haar liegen und sich langsam an diesem vorbeibewegen [21]. Die Prävalenz der Pediculosis capitis in Industrieländern wird auf 1-3\% geschätzt. Im Gegensatz zu bekannten Vektoreigenschaften der Kleiderlaus, galt die Kopflaus bisher nicht als Überträger von Erregern. Bei nepalesischen Kindern gelang jedoch kürzlich erstmals der DNA-Nachweis von Bartonella quintana, dem Erreger des Wolhyn-Fiebers, in Pediculus humanus capitis [148]. Eine Übertragung des Wolhyn-Fiebers durch die Kopflaus scheint somit möglich zu sein, wohl aber nur bei hoher Durchseuchung der Bevölkerung [148]. Die Pediculosis capitis kann symptomlos verlaufen, führt jedoch nach mehreren Wochen oft zu Juckreiz, Exkoriationen mit bakterieller Sekundärinfektion, zervikaler Lymphadenopathie und Konjunktivitis. Auch Exantheme im Sinne eines Pedikulids, die einem Virusexanthem ähneln können, sind beschrieben [85]. Das feuchte Durchkämmen der Kopfhaut ist der bloßen Inspektion bei der diagnostischen Erregersuche überlegen [35, 120]. Für eine bestehende Infektiosität einer Kopflausinfestation spricht der Nachweis von Nissen mit 0,5 cm Abstand vom Haarboden [194]. Der Abstand der Nissen von der Kopfhaut erlaubt eine Datierung der Erstinfektion. Da die Kopfhaare etwa $1 \mathrm{~cm}$ pro Monat wachsen und die Larven innerhalb von 10 Tagen aus den Nissen geschlüpft sind, stellen Nissen, die weiter als $1 \mathrm{~cm}$ von der Kopfhaut entfernt sind, in unseren Breitengraden kein Infektionsrisiko mehr dar [143]. In wärmen Klimazonen können lebende Nissen noch bis zu $20 \mathrm{~cm}$ entfernt von der Kopfhaut beobachtet werden [115].

Permethrin, ein synthetisches Pyrethroid-Derivat (InfectoPedicul, 0,5\% Permethrin) wird topisch auf das feuchte Haar für 30 Minuten appliziert und gilt gegenüber natürlichen Pyrethroidextrakten (Goldgeist forte) als besser verträglich. Permethrin wie auch natürliche Pyrethroide interferieren mit dem neuronalen Natriumtransport und bedingen eine Depolarisation der Neuronenmembranen der Arthropoden, was schließlich zur respiratorischen Paralyse führt $[85,116]$. Das mittlerweile in Deutschland verbotene Organochlorid Lindan hat neurotoxisches Potential und führt ebenfalls zur respiratorischen Paralyse der Arthropoden. Aufgrund der bekannten Neurotoxizität beim Menschen nach unsachgemäßer Anwendung wird Lindan in den USA und auch in der Europäischen Union mit zunehmender Zurückhaltung betrachtet [85, 143]. Aus Sicherheitsgründen sollte die Anwendung topischer Pedikulizide nach Erstapplikation wiederholt werden, um überlebende Nissen abzutöten [85]. Der optimale Zeitraum einer Reapplikation von Pedikuliziden wurde mit 10 Tagen nach der Erstbehandlung bestimmt, da Larven nach 5 bis 11 Tagen schlüpfen. Die Wirksamkeit einer Nachbehandlung mit einem kürzeren Intervall von nur 6 bis 8 Tagen war der Effizienz einer Nachbe- 
handlung nach 10 Tagen mit mehr als 90\% unterlegen [121]. Ein zunehmendes Problem in Deutschland und international sind Pedikulizidresistenzen [85, 143]. Bekannte Mechanismen der Pyrethroidresistenz ist die Glutathion-S-Transferase-abhängige Resistenz sowie die Monooxigenase-abhängige Resistenz, die $\mathrm{zu}$ einem verstärkten Wirkstoffmetabolismus wie von Piperonylbutoxyd führt [7]. In den USA und im europäischen Ausland wird der Organophosphatcholinesteraseinhibitor Malathion propagiert [19, 116]. In den USA wird Malathion in einer Konzentration von $0,5 \%$ als schnell und hoch wirksames Pedikulizid empfohlen, das nach 10minütiger Applikation zu einer 88\%igen Abtötung von Läusen und nach 20minütiger Verweildauer zu 100\%iger Abtötung der Parasiten führt [19]. Malathion ist in Deutschland nicht zugelassen und kann auch zu stärkeren Nebenwirkungen führen. Zunehmende Resistenzen gegen Malathion und Permethrin werden bereits in England beobachtet [37]. Vielversprechend könnte der Einsatz von Ivermectin sein, das sowohl topisch in 1\%iger Konzentration als auch oral in der üblichen Dosis von $200 \mu \mathrm{g} / \mathrm{kg}$ Körpergewicht Läuse effektiv abtötet $[19,58,199]$. Bei oraler Gabe ist eine Nachbehandlung nach 8 Tagen erforderlich [19], da Ivermectin nicht ovizid ist und über die Blutmahlzeit vom Parasiten aufgenommen werden muss. Eine Zulassung von Ivermectin für die Indikation Pedikulose liegt in Deutschland nicht vor. Tabelle 3 informiert über die derzeit in Deutschland zur Behandlung der Pediculosis capitis zugelassenen antiparasitäten Mittel. Daneben gibt es im Handel noch eine Reihe von Shampoos (Wash Away, Paranix), die wirksam und verträglich sind. Neue therapeutische Strategien in der Entwick- lung von Pedikuliziden könnten Interferenzen mit dem proteinbiochemischen Mechanismus der Nissenablage und des Sauerstofftransfers zu den Nissen und schlüpfenden Larven nutzen [18].

Bettlaken, Felle und Mützen sollten im Falle von Massenbefall bei einer Temperatur über $50^{\circ} \mathrm{C}$ in der Waschmaschine gewaschen werden, um Läuse effektiv zu eradizieren [76]. Nicht waschbare Gegenstände wir Kämme und Bürsten können im Gefrierfach bei $-10^{\circ} \mathrm{C}$ über zwei Tage dekontaminiert werden [143]. In den meisten Fällen bleibt die Kopflaus aber auf der Kopfhaut, so dass Dekontaminationen von Gegenständen meist keinen großen Effekt haben und nicht generell empfohlen werden.

\section{Pediculosis corporis}

Lausinfektionen begleiten die Evolution des Menschen möglicherweise seit seiner Entwicklung. Molekulargenetische Untersuchungen haben gezeigt, dass die Kleiderlaus sich vor 70000 bis 30000 Jahren von der Kopflaus differenziert hat, in einem Zeitraum, als der Homo sapiens sein Fell reduziert hat [143]. Bei Obdachlosen, Flüchtlingen und Betroffenen von Naturkatastrophen ist die Kleiderlaus als Vektor ernster Infektionskrankheiten gefürchtet, insbesondere von Rickettsia prowazekii (Flecktyphus) und Bartonella quintana, dem Erreger des Wolhyn-Fiebers und Verursacher einer bakteriellen Endokarditis [39, 77, 159]. Bei 57 Obdachlosen in Paris fand sich bei mehr als der Hälfte der Untersuchten eine Seropositivität für Bartonella quintana, die zur Anzahl der Jahre in Obdachlosigkeit und Episoden von Pedicu-

Tabelle 3. In Deutschland als Medikamente zugelassene Pedikulizide

\begin{tabular}{|c|c|c|c|c|}
\hline Substanz & Konzentration & Handelsname & Kontraindikationen & Erstanwendung \\
\hline Permethrin & $0,5 \%$ & $\begin{array}{l}\text { InfectoPedicul- } \\
\text { lösung }\end{array}$ & $\begin{array}{l}\text { Säuglinge in den ersten } \\
2 \text { Lebensmonaten }\end{array}$ & $\begin{array}{l}\text { In feuchtes Haar einrei- } \\
\text { ben, nach 30-45 min } \\
\text { auswaschen }\end{array}$ \\
\hline $\begin{array}{l}\text { Pyrethrumextrakt } \\
\text { Piperonylbutoxid } \\
\text { Chlorokresol }\end{array}$ & $\begin{array}{l}0,3 \% \\
0,7 \% \\
0,9 \%\end{array}$ & $\begin{array}{l}\text { Goldgeist forte } \\
\text { Lösung }\end{array}$ & $\begin{array}{l}\text { Schleimhautkontakt und } \\
\text { Augenkontakt }\end{array}$ & $\begin{array}{l}\text { Haar durchtränken und } \\
\text { nach } 30-45 \text { min aus- } \\
\text { waschen }\end{array}$ \\
\hline $\begin{array}{l}\text { Allethrin und } \\
\text { 5-[2-(-(2-Butoxy-ethoxy)- } \\
\text { ethoxy- methyl]-6-propyl- } \\
\text { 1,3-benzodioxol }\end{array}$ & $\begin{array}{l}0,66 \% \\
2,64 \%\end{array}$ & Jacutin N pray & $\begin{array}{l}\text { Säuglinge, Augen } \\
\text { und Schleimhäute, } \\
\text { Asthmatiker, broncho- } \\
\text { pulm. Erkr. }\end{array}$ & $\begin{array}{l}\text { Haarsträhnen einsprü- } \\
\text { hen, nach } 30 \text { min aus- } \\
\text { waschen }\end{array}$ \\
\hline Lindan* & $0,3 \%$ & Jacutin Gel & $\begin{array}{l}\text { Anfallsleiden, Augen- } \\
\text { und Schleimhautkontakt }\end{array}$ & $\begin{array}{l}15 \mathrm{~g} \text { in feuchtes Haar } \\
\text { einreiben, nach } 3 \text { Tagen } \\
\text { auswaschen }\end{array}$ \\
\hline
\end{tabular}

* Der Wirkstoff Lindan ist ab 2007 in Deutschland verboten. 
losis corporis korrelierte [60]. Bartonella-quintanaSeropositivität wurde auch bei $16,7 \%$ der Obdachlosen in Tokyo gefunden [147]. Es gibt Anzeichen dafür, dass der Vektor von Bartonellen die Erkrankungsmanifestation mitbestimmt. So wird bei Übertragung der Bartonellen durch den Floh (meist Katzenfloh) die Katzenkratzkrankheit oder bazilläre Angiomatose hervorgerufen, wohingegen die Kleiderlaus vermehrt zur Endokarditis führt [86]. Kleiderläuse sind bedeutsame Vektoren des Rückfallfiebers, des Wolhyn-Fiebers als auch des epidemischen Typhus, der durch Rickettsia prowazekii hervorgerufen wird $[85,146]$. Die Erregerübertragung erfolgt durch Einatmen oder Einreiben von kontaminiertem Läusekot.

Patienten mit Kleiderlausinfestationen weisen häufig eine stark ekzematisierte und exkorriierte Haut unter dem Bild einer Cutis vagantium auf. Kleiderläuse und Nissen finden sich an den Kleidersäumen im Bereich der Hüften. Die Behandlung besteht in der Entfernung oder Entwesung der kontaminierten Kleidung. Foucault et al. [52] berichteten über einen dramatischen Therapieerfolg bei Obdachlosen mit Pediculosis corporis in Marseille durch dreimalige orale Gabe von je $12 \mathrm{mg}$ Ivermectin in einem siebentägigen Intervall. Die Zahl der Läuse fiel durch diese Therapie von 1898 auf 6, die Prävalenz der Infestierten sank von $84,9 \%$ auf 18,5\%. Kleiderwechsel und Entwesung bleibt aber unumgänglich.

\section{Pediculosis pubis}

Die Filzlausinfestation durch Phthirus pubis zählt zu den STD-Erkrankungen. Typisch sind die am unteren Teil des Abdomen anzutreffenden Maculae ceruleae. Bei Nachweis einer Pediculosis pubis sollte stets bedacht werden, dass 30\% der Infestierten zudem an einer anderen sexuell übertragbaren Erkrankung leiden, weshalb ein STD-Screening erfolgen sollte [85]. Entsprechend einer retrospektiven Studie von 62 Erwachsenen mit Filzlausinfestation zeigte sich eine zweifach gesteigerte Prävalenz von Chlamydien- und Gonokokkeninfektionen [134].

Bei der topischen Behandlung mit 5\% Permethrin sollte an die gründliche Mitbehandlung rektaler Haare gedacht werden, deren Aussparung ein Therapieversagen bedingen kann [17]. Filzläuse sind auch für die forensiche Medizin von Bedeutung, da menschliche mitochondriale DNA aus ihnen extrahiert und sequenziert werden konnte [103]. Vor kurzem wurde erstmals über Pyrethrinresistenz von Filzläusen berichtet [160]. Die amerikanischen Kollegen Burkhart und Burkhart [17] empfehlen bei Filzlausbefall die zweimalige orale Verabreichung von Ivermectin in einer Dosierung von $250 \mu \mathrm{g} / \mathrm{kg}$ Körpergewicht im Abstand von einer Woche als Mittel der Wahl. Eine Mitbehandlung der Sexualpartner sollte bedacht werden. Eine Phthiriasis palpebrarum konnte durch orale Gabe von Ivermectin zur Abheilung gebracht werden [16]. Ein radikales Abrasieren der Haare wirkt $100 \%$ ig. Es ist zu berücksichtigen, dass Ivermectin in Deutschland für die Behandlung von Pedikulosen nicht zugelassen ist.

\section{Skabies}

Skabies stellt eine häufige, weltweit verbreitete Epizoonose dar, die nach einer Epidemie zwischen 1944 und 1946 seit den 70er Jahren erneut ansteigt und besonders intensiv HIV-Infizierte befällt $[50,163]$. Die Erkrankung wird durch die Skabiesmilbe Sarcoptes scabiei var. hominis hervorgerufen.

\section{Permethrin zur topischen Skabiesbehandlung}

Als Mittel der Wahl bei Skabies gilt derzeit das synthetische Pyrethroid Permethrin mit der chemischen Bezeichnung 3-Phenoxybenzyl ( \pm )-cis-trans-3-(2,2dichlorovinyl)-2,2dimethyl-cyclopropankarboxylat. Die akarizide Wirkung von Permethrin beruht auf seiner neurotoxischen Wirkung durch Verlängerung des Natrium-Einwärtsstroms an den Nervenmenbranen [50]. Die gute und sichere therapeutische Wirkung von Permethrin bei Skabies wurde schon 1986 von Taplin et al. [171] in den USA und von Haustein [65] im Jahr 1991 in Leipzig herausgestellt. Es dauerte 14 Jahre, bis der topischen Permethrintherapie bei Skabies in Deutschland durch die Ergebnisse einer multizentrischen Studie zum Durchbruch verholfen wurde [63]. Die Heilungsquote der 106 Patienten von 13 Zentren betrug nach vier Wochen 95,1\%. Die Studie belegte die Wirksamkeit und Sicherheit von $5 \%$ iger Permethrin-Creme (InfectoScab ${ }^{\circledR} 5 \%$ Creme) bei Skabies im Erwachsenen-, Kindes- und Säuglingsalter [63]. In der Regel reicht eine einmalige Behandlung mit 5\%iger Permethrin Creme über Nacht (8-12 Stunden) mit anschließendem Duschbad und optionaler Wiederholungsbehandlung nach 10 bis 14 Tagen bei Nachweis persistierender aktiver Läsionen aus. Ausreichende Erfahrungen bei Kindern bis zwei Jahre liegen nicht vor. Daher sollte die Behandlung in dieser Altersgruppe nur unter engmaschiger ärztlicher Aufsicht erfolgen. Im Tierversuch ergaben sich 
keine Hinweise auf eine embryo- oder fetotoxische Wirkung von Permethrin. Da bislang keine ausreichenden Erfahrungen über die Anwendung während der Schwangerschaft und Stillzeit vorliegen, sollte Permethrin nur nach sorgfältiger Indikationsstellung angewendet werden. Stillende Mütter sollten aus Sicherheitsgründen nach der Anwendung eine Stillpause von drei Tagen einhalten (Fachinformation InfectoScab $\left.{ }^{\circledR}\right)$. Im Vergleich zu anderen zugelassenen Antiskabiosa wie 0,3\% Lindan, 10\% und 25\% Benzylbenzoat sowie $10 \%$ Crotamiton zeichnet sich Permethrin 5\% aufgrund seiner Wirksamkeit und relativ geringen Nebenwirkungen aus und wird zur Behandlung der Skabies in der frühkindlichen Phase, Schwangerschaft und Stillzeit und für Patienten mit neurologischen Erkrankungen und Lindanresistenzen empfohlen [50, 135, 136]. Lindan wurde bereits vom britischen Markt zurückgezogen und darf in Deutschland aufgrund einer EU-Verordnung nur noch bis 2007 in den Handel gebracht werden. Mit Permethrin steht eine wirksame Alternative zur Verfügung, die als Mittel der Wahl bei der Skabiestherapie empfohlen wird [63]. Permethrin 5\% Creme (InfectoScab 5\% ${ }^{\circledR}$ ) ist seit Oktober 2004 zur Skabiesbehandlung in Deutschland zugelassen.

Ivermectin

Ivermectin (22,23-Dihydroavermectin B1) ist ein synthetisches Derivat von Avermectin, einem antiparasitär wirksamen makrozyklischen Lacton aus Streptomyces avermitilis $[38,178]$. Ivermectin blockiert den Transmittertransport an Synapsen, die glutaminerge Anionenkanäle und GABAerge Chloridkanäle betreffen. Ivermectin führt zur vermehrten präsynaptischen Freisetzung von GABA ( $\gamma$-Aminobuttersäure) und zur vermehrten Bindung von GABA an dem postsynaptischen Rezeptor [38]. Hierdurch kommt es zur Unterbrechung der neuronalen Impulsweiterleitung, zur Paralyse und schließlich zum Tod des Parasiten. Unerwünschte Nebenwirkungen sind selten, da die Substanz keinen Einfluss auf das GABAerge System beim Menschen hat, weil sie nicht in das zentrale Nervensystem aufgenommen wird. Ivermectin ist Mittel der Wahl zur Behandlung vieler Darmnematoden und auch der Onchozerkose, bei der aber nur eine Sterilisieung der Wurmweibchen eintritt, nicht deren Abtötung. Für die Skabiesbehandlung liegt in Deutschland keine Zulassung vor. Bewährt hat sich Ivermectin bei der oralen Behandlung der Scabies crustosa (norvegica) $(200 \mu \mathrm{g} / \mathrm{kg} \mathrm{KG})$ sowie bei Heimepidemien, da durch die orale Gabe eine effektive und synchrone Behandlung aller Befallenen und Kontaktpersonen erfolgen kann. Die topische Applikation von Ivermectin 1\%ig in Propylenglykol in einer Dosis von $400 \mu \mathrm{g} / \mathrm{kg}$ mit Wiederholungsbehandlung nach einer Woche führte bei 12 Erwachsenen und 20 Kindern zur vollständigen Abheilung der Skabies [184]. Die topische Behandlung war sicher, wirksam, kostengünstig und nebenwirkungsarm. Ivermectin ist in Deutschland aber weder für die orale noch für die topische Behandlung der Skabies zugelassen, erfordert daher die persönliche Aufklärung und Zustimmung des Patienten im Sinne eines Heilversuchs.

Ivermectin interagiert mit dem $\mathrm{ABC}$ Multidrug Transporter P-Glycoprotein, das den transmembranösen Transfer von Ivermectin vermittelt. Ivermectinresistenzen werden durch Expression von MDR (Multiple drug resistance)-Proteinhomolgen induziert [95]. Bisher wurden bei Sarcoptes scabiei neun ABC-Transporter der Unterfamilien A, B, C, E, F und $\mathrm{H}$ identifiziert. Als möglicher Mechanismus von Ivermectinresistenzen in zwei Fällen von Scabies crustosa wurde eine Beteiligung des ABC-B-Transporters P-Glycopotein vermutet [118].

\section{Infestation durch Flöhe}

Flohbefall des Menschen ist in unseren Breiten in erster Linie auf den Kontakt zu Hunden und Katzen zurückzuführen. Mit steigender Tendenz werden in Deutschland 5 Millionen Hunde und 6,5 Millionen Katzen gehalten [186]. Der Katzenfloh (Ctenocephalides felis) (Abb. 5) ist derzeit der häufigste Floh, der den Menschen befällt, da er aufgrund seiner geringen Wirtsspezifität gleichermaßen Hund und Katze heimsucht und als Nebenwirt den Menschen akzeptiert. In einer Studie von 299 Hunden fanden Tierärzte in $71,2 \%$ den Katzenfloh, in 14,7\% den Igelfloh (Achaeopsylla erinacei) und in nur 3,4\% den Hundefloh (Ctenocephalides canis). Der Rest bestand aus Mischinfestationen oder anderen Floharten. Bei den 344 untersuchten Katzen meldeten die Tierärzte den Katzenfloh mit 83,4\%, den Igelfloh mit 5,0\% und den Rest mit Mischinfestationen oder anderen Floharten. Mehr als 80\% der Flohprobleme werden durch den Katzenfloh verursacht. Der Menschenfloh (Pulex irritans) ist in Nord- und Mitteleuropa extrem selten geworden. Vogelflöhe (Ceratophyllus gallinae) halten sich in den Nestern ihrer Wirte auf. 95\% aller Floharten bevorzugen dagegen Säugetiere, insbesondere Kleinnager. Gefährlich für den Menschen ist der tropische Rattenfloh (Xenopsylla cheopis), der als Über- 


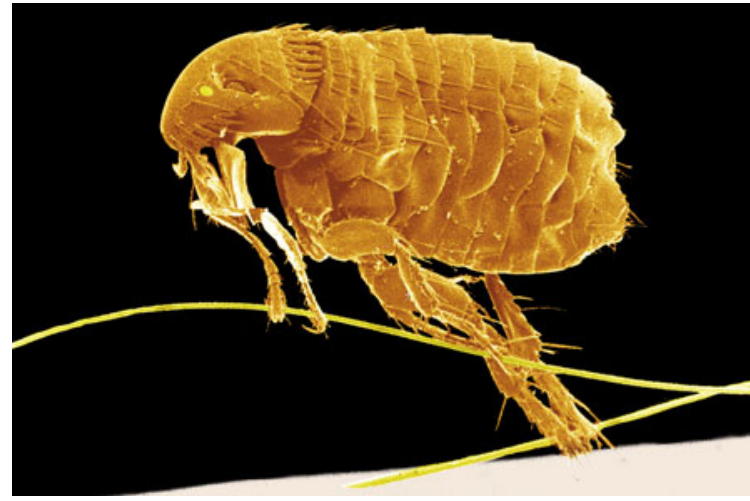

Abb. 5. Katzenfloh (Ctenocephalides felis), entnommen mit freundlicher Genehmigung aus [114]

träger der Bubonen- und Lungenpest vornehmlich im Mittelalter zu Epidemien führte. Flohbefall kommt bei $73 \%$ der Hunde in Einzeltierhaltung vor. Jedoch nur bei 50,2\% der Katzen mit Flohbefall stammen aus Einzeltierhaltungen. Der Befall des Menschen durch den Katzenfloh ist aufgrund seiner extremen Sprungkraft mit 140facher Erdbeschleunigung beim Absprung bis in eine Höhe von $30 \mathrm{~cm}$ und bis zu einer Weite von $50 \mathrm{~cm}$ möglich. Für die zoologische Bestimmung der Floharten sind die Kämme (Ctenidien) am Kopf beziehungsweise im Nacken von Bedeutung. Durch Klauen und Borsten an den Beinen können sich die Flöhe nach dem Absprung am Wirt festklammern. Der Katzen- und Rattenfloh können in tropischen Ländern die Erreger der Pest, Schweinepest, Tularämie und Poliomyelitis übertragen. Der Rattenfloh (Xenopsylla cheopis) gilt in urbanen Stadtgebieten mit großen Rattenpopulationen als Überträger von Rickettsia mooseri, dem Erreger des murinen Fleckfiebers. Der Katzenfloh wirkt als wichtiger Überträger von Bartonella henselae, Bartonella clarridgeiae und Bartonella koehlerae [31]. Einige Bandwürmer benutzen auch den Katzen-, Hunde- und Rattenfloh als Zwischenwirt, was bei oraler Aufnahme durch Kleinkinder im Krabbelalter von Bedeutung ist [111]. In seltenen Fällen wurden nach Flohstichen auch Pilzinfektionen beobachtet.

Bei der Flohprophylaxe und -bekämpfung ist $\mathrm{zu}$ beachten, dass die Flohpopulation nur zu 5\% aus Adulten, 10\% aus Puppen, 35\% aus Larven und 50\% aus Eiern besteht, was eine Bekämpfung der Infestation am Tier und vor allem dessen Umfeld erfordert [186]. Neben Insektizid-imprägnierten Hunde- und Katzenhalsbändern stehen flüssige Insektizide zur Spot-on-Applikation beim Tier zu Verfügung, die beim Tierarzt erhältlich sind. Zur prophylaktischen
Flohbekämpfung im Lebensraum des Wirtstieres kommen im Wesentlichen zwei Substanzgruppen in Betracht, die Juvenilhormone und Chitinsynthesehemmer.

\section{Cimicosis}

Die gewöhnliche Bettwanze, Cimex lectularius, gehört zur Familie der Cimicidae. Sie ist für die meisten Wanzenstiche beim Menschen verantwortlich und kommt weltweit vor. Innerhalb der letzten Jahre wird eine Zunahme im Vereinigten Königreich und den USA registriert [173]. Das vermehrte Vorkommen der Bettwanze innerhalb der letzen Jahre wird auf die Zunahme des internationalen Reiseverkehrs und der Migration zurückgeführt [130]. Stiche der nachtaktiven Wanzen führen an der Haut zu linear angeordneten erythematösen Knoten, nicht selten zu Bullae. Kürzlich berichteten Leverkus et al. [96] über einen Patienten mit rezidivierenden bullösen Wanzenstichen, bei dem eine spezifische IgE-vermittelte Hypersensitivität gegen das $32 \mathrm{kDa}$ Speichelprotein Nitrophorin nachgewiesen werden konnte. Obwohl die Mehrzahl der Stichreaktionen von Arthropoden durch eine Vielzahl bisher weitgehend unbekannter Mediatoren bedingt ist [9], konnte im Fall des Patienten mit bullöser Cimicosis eine IgEvermittelte Reaktion gegen das Speichelprotein Nitrophorin nachgewiesen werden. Während des Blutsaugens bedient sich Cimex lectularius der vasodilatierenden Wirkung von Stickstoffoxid, das gebunden an das Hämprotein Nitrophorin im Speichel des Parasiten zum Wirtsgewebe transportiert wird [180]. Zur Bekämpfung sollte der Schädlingsbekämpfer herangezogen werden, da die nachtaktiven Tiere im Schutz von Spalten und Ritzen den Tag verbringen.

\section{Kutaner Loxoscelismus}

Die braune Einsiedlerspinne, Loxosceles reclusa, ist in den USA weit verbreitet, Loxoceles rufescens im Mittelmeergebiet. Diese Spinnen leben vorwiegend im Haus. Ihr Gift enthält eine Sphingomyelinase D, die schwere Dermatonekrosen und Ulzerationen hervorrufen kann. Strukturelle Untersuchungen des katalytischen Mechansimus der Sphingomyelinase D zeigen eine evolutionäre Beziehung zu Glyzerophosphodiester-Phosphodiesterasen [122]. Kürzlich konnte gezeigt werden, dass das Loxoscelesvenom zu einer komplementabhängigen (C5a und Membran- 
attackkomplex) Dermatonekrose, Neutrophileninfiltration und Expression der endogenen Gelatinase (MMP-9) führt [170]. Die Aktivierung der Matrixmetalloproteinasen 2 und 9 (MMP2 und -9) sind die Hauptursache der Keratinozytenapoptose und nachfolgender proteolytischer Gewebsdestruktionen. Da Tetrazykline Metalloproteinasen inhibieren, besteht die Möglichkeit gewebedestruierende Prozesse nach Giftübertragung durch rechtzeitige Tetrazyklingabe $\mathrm{zu}$ verhindern [127]. In Deutschland führen Stiche der nur $14 \mathrm{~mm}$ froßen Dornfingerspinne (Cheiracanthium punctorium) zu tagelang anhaltenden Schmerzen.

\section{Leishmaniosen}

Leishmaniosen kommen auf allen Kontinenten mit Ausnahme Australiens vor. Die Verbreitung erfolgt durch tag- und nachtaktive weibliche Schmetterlingsmücken (Phlebotomen), die während ihrer Blutmahlzeit die Protozoen übertragen. Der vordere Mitteldarm von leishmanieninfizierten Schmetterlingsmücken wird durch ein sekretorisches Gel parasitären Ursprungs blockiert. Die Transmission der Erreger der kutanen Leishmaniasis wird durch Regurgitation von filamentösem Proteophosphoglycan (fPPG), einer Komponente des sekretorischen Gels der Promastigoten, gefördert [144]. Die intrazelluläre Infektion von Gewebsmakrophagen persistiert innerhalb von Phagolysosomen wahrscheinlich trotz Behandlung lebenslang [123]. Die Erreger sind im gesamten Mittelmeerraum relativ häufig anzutreffen. Gegenwärtig wird eine Epidemie kutaner Leishmaniose in Afghanistan und Pakistan und eine Epidemie viszeraler Leishmaniose in Indien und im Sudan beobachtet [123]. Das Auftreten in Flüchtlingslagern wie in Palästina ist relativ häufig. Die Inzidenz der kutanen Leishmaniose erreicht weltweit zwei Millionen neue Fälle pro Jahr, davon $90 \%$ in der Alten Welt und 10\% in der Neuen Welt [45]. Kürzlich wurde über einen neuen Focus kutaner Leishmaniose im Norden Israels berichtet, der nicht wie gewöhnlich durch Leishmania major, sondern durch Leishmania tropica verursacht wird [154]. In Indien werden zunehmend Antimonresistente viszerale Leishmaniosen registriert [123]. Dies führte zu erfolgreichen klinischen Studien mit Pentamidin und Amphothericin B. Zu Verminderung der Nephrotoxizität von Amphothericin B wurden kolloidale Zubereitungen und Lipidformulierungen entwickelt. Sehr wirksam ist das Alkylphosphocholin Miltefosin, das in klinischen Studien eine Wirksamkeit von $94-97 \%$ zeigte [156]. Hunde sind ein wichtiges Erregerreservoir für die viszerale Leishmaniose des Menschen [181]. Es konnte in Endemiegebieten gezeigt werden, dass Deltamethrinimprägnierte Hundehalsbänder Haushunde vor der Infektion mit Leishmania infantum schützen. Sie tragen zur Eindämmung der viszeralen Leishmaniose bei [110]. Eine interessante neue Alternative zur intraläsionalen Natriumstiboglukonatbehandlung oder photodynamische Therapie der kutanen Leishmanisiose [46] zeichnet sich durch die lokale Thermotherapie mit Radiofrequenzwellen ab. Eine 30 Sekunden dauernde Behandlung mit Radiofrequenzen von $6,78 \mathrm{mHz}$ mit einer Hauterwärmung auf $50^{\circ} \mathrm{C}$ führte bei Nachuntersuchungen nach 100 Tagen zu einer Heilungsrate von $69,4 \%$ im Vergleich zu einer Heilungsrate von $75,3 \%$ der mit Antimon intraläsional behandelten Patienten [141]. Eine weitere Option zur Behandlung kutaner Leishmaniose könnte die lokale Photochemotherapie (PUVA) darstellen. Mit metazyklischen Promastigoten von Leishmania mexicana und mit Amastigoten von Leishmania major kontaminierte Thrombozytenkonzentrate wiesen nach Applikation von $150 \mu \mathrm{mol} / \mathrm{l}$ des Psoralens Amotosalen und nachfolgender UV-A-Bestrahlung mit $3 \mathrm{~J} / \mathrm{cm}^{2}$ eine mehr als 10000-fachen Reduktion der Lebensfähigkeit der Leishmanien auf [41]. Die photochemische Behandlung von kontaminierten Thrombozytenkonzentraten inaktivierte gleichermaßen promastigote als auch amastigote Stadien, wobei letztere sich intrazellulär im Menschen vermehren.

\section{Onkogene Wirkung von Moskitostichen}

Die vor allem in Japan beobachtete Hypersensitivität auf Mückenstiche (HMB) ist durch starke lokale Intoleranzreaktionen mit Erythem, Ödem, Blasen und sogar Ulzeration mit Narben gekennzeichnet. Ferner treten systemische Reaktionen mit hohem Fieber, Lymphadenopathie und Hepatosplenomegalie auf $[149,197]$. Viele Patienten mit Hypersensitivität auf Mückenstiche sterben an lymphoproliferativen Erkrankungen [68]. Die Lymphoproliferation sowie die NK-Zell-Leukämie/NK-Zell-Lymphom sind auf transformierte Ebstein-Barr-Virus (EBV)-DNA-positive natürliche Killerzellen (NK-Zellen) zurückzuführen $[75,176]$. Latentes Membranprotein 1 (LMP1) ist das wichtigste virale EBV-Transformationsprotein, dessen Gen in EBV-infizierten NK-Zellen exprimiert wird [30]. LMP1 aktiviert verschiedene Signaltransduktionswege während der onkogenen Transformation [22]. Asada et al. [3] konnten kürz- 
lich zeigen, dass Speicheldrüsenextrakte der Tigermücke (Aedes albopictus) zu einer Proliferation von CD4+-T-Zellen, nicht aber von NK-Zellen führte. Die Kokultivierung dieser mit Aedes albopictus Speichelextrakten stimulierten CD4+-T-Zellen mit NKZellen führten jedoch zur vermehrten Expression des viralen Onkogens LMP1 in EBV-infizierten NKZellen. Diese Befunde verdeutlichen, dass Moskitoantigene an der Onkogenese EBV-infizierter NKZellen beteiligt sind, indem sie durch sensibilisierte CD4+-T-Zellen die Expression des viralen Onkogens LMP1 induzieren [3].

\section{Die Katze als Erregerüberträger}

Katzen und Hunde sind die in Deutschland am häufigsten gehaltenen Haustiere. Mit steigender Tendenz werden in Deutschland 6,5 Millionen Katzen gehalten [186]. Sie transportieren den Katzenfloh in den Wohnraum des Menschen. Da der Katzenfloh gegenwärtig die häufigste Flohspezies ist, die den Menschen befällt, besteht durch Katzenhaltung die Gefahr der Übertragung von Batonellaspezies [31]. Die Inokulation von Bartonella henselae erfolgt primär durch Kratzverletzung der Haut durch erregerkontaminierte Kratzenkrallen. Bartonella henselae reproduziert sich im Verdauungstrakt des Flohs und überlebt mehrere Tage in den Flohfäzes [11]. Nur Katzen, die mit Flohfäzes kontaminiert wurden, entwickelten eine Bakteriämie [51]. Die experimentellen Befunde unterstützen die Vermutung, dass nur Katzen, die zuvor mit Bartonella henselae infizierten Katzenflöhen infestiert waren, durch Kontamination ihrer Krallen mit Flohfäzes Bartonella henselae auf den Menschen übertragen [31].

Katzen gelten als wichtigster Überträger von Microsporum canis. In einer bundesweiten Umfrage in Deutschland im Jahr 1998 wurden zoophile Dermatophytenarten in $81,2 \%$ und anthropophile Spezies in 18,8\% der Tinea capitis identifiziert [174]. Microsporum canis wurde bei $54,8 \%$, Trichophyton mentagrophytes in $14,7 \%$, Trichophyton verruosum in $8,1 \%$, Trichophyton violaceum in 6,1\% und Trichophyton tonsurans in 3,8\% der 394 bundesweit untersuchten Fälle von Tinea capitis festgestellt [174]. Das Erregerspektrum hat sich in den letzten Jahren nicht wesentlich geändert (Prof. Dr. Tietz, persönliche Mitteilung 2006). Auch Sporothrix schenckii, der Erreger der Sporotrichose, der meist im Erdreich, Pflanzen oder organischem Material vorkommt, kann durch Kratzen oder Biss einer Katze übertragen werden. In Rio de Janeiro wurde im Zeitraum 1998 bis 2001 eine Epi- demie der Spororthrichosis beobachtet. Von 178 Infizierten hatten 156 Kontakt zu Katzen, 97 Patienten erinnerten sich an Kratzeffekte oder Katzenbisse als mögliche Inokulation mit dem Pilz [34]. Bei der Mehrzahl der Patienten entwickelte sich die lymphokutane Form der Sporothrichosis [152]. Bei infizierten Katzen konnte Sporothrix schenckii zu 100\% aus Hautläsionen, zu 66,2\% aus der Nasenhöhle, zu 41,8\% aus der Mundhöhle und zu 39,5\% von den Katzenkrallen isoliert werden $[151,166]$.

Bei Haus- und Wildkatzen kommen latente Darminfektionen mit dem Einzeller Toxoplasma gondii weltweit mit hoher Prävalenz vor [172]. In Deutschland liegt die Seroprävalenz zwischen 36 und $46 \%$ bei Hauskatzen sowie zwischen 56 und $66 \%$ bei streunenden Katzen und Wildkatzen [67]. Toxoplasma gondii ist ein intrazellulär lebendes Protozoon mit einem zweiwirtigen Entwicklungszyklus, bei dem Katzen Endwirt sind und Oozysten im Kot ausscheiden, die im Freien nach drei bis fünf Tagen zur Infektionsfähigkeit heranreifen. Nur die Erstinfektion in der Schwangerschaft kann in $50 \% \mathrm{zu}$ einer pränatalen Infektion des Feten führen, in deren Folge es zu schweren fetalen Schädigungen oder auch zu Spätschäden beim Kind (Auge, Gehör, Gehirn) kommen kann [59]. Schwangere, Immunsupprimierte und vor allem AIDS-Patienten sollten rohes und unvollständig gegartes Fleisch als auch Katzenkontakt meiden und Gemüse und Obst gut waschen. Bei AIDS-Patienten mit einer CD4-Zellzahl $<100-200 / \mu l$ erfolgt eine Primärprophylaxe mit Cotrimoxazol.

Katzen können auch das Kuhpockenvirus, ein Orthopoxvirus, übertragen, das in europäischen Ländern vorkommt. Die Virusinfektion ist durch das Auftreten genabelter Vesikel mit umgebendem induriertem erythematösem Ödem innerhalb der Kratzverletzungen einer Katze gekennzeichnet [61]. Meist treten eine regionale Lymphadenopathie, Fieber als auch grippeartige Symptome auf. Differenzialdiagnostisch ist an Anthrax, Katzenkratzkrankheit und bullöse Impetigo zu denken. Eine lokale antiseptische Behandlung ist meist ausreichend. Die Läsionen heilen mit varioliformen Narben ab.

\section{Die Fel d1-allergen-freie Katze}

Fel d1, das Hauptallergen der Hauskatze (Felis domesticus), verantwortlich für allergische Rhinokonjunktivitis und allergisches Asthma bronchiale bei Sensibilisierten, ist auf molekularer Ebene charakterisiert 
[81, 153]. Fel d1 wird hauptsächlich von Talgdrüsen produziert, zu einem geringeren Teil von Basalzellen der Katzenepidermis und Speicheldrüsen und wird an der Hautoberfläche und im Fell deponiert [27]. Die Synthese von Fel d1 erfolgt primär durch Sebozyten, da eine Kastration zum Abfall der Sebum- und Fel d1-Synthese führt und eine Testosteronsubstitution wieder zum Anstieg der Fel d1-Synthese [28, 200]. Das Fel d1-Gen normaler Katzen ist verantwortlich für die Synthese des Feld1-Glykoproteins. Der Firma Allerca Inc. ist es gelungen, Katzen mit modifizierten Fel d1-Genen zu züchten, deren veränderte Fel d1Proteine nicht mehr allergen wirken (Internet-Information www.allerca.com). Die angewandte clonierungsfreie GD-Methode hat keine gesundheitlichen Risiken für die hypoallergenen Katzen und stellt einen allergologischen Meilenstein in der Prävention eines wichtigen Innenraumallergens dar.

\section{Der Hund als Erregerüberträger}

In Deutschland werden 5 Millionen Hunde gehalten. Die häufigsten bei Hunden vorkommenden Zecken sind Ixodes ricinus, Dermacentor reticulatus und Rhipicephalus sanguineus (Abb. 1a-c). Die, durch Zecken übertragenen Erkrankungen wurden bereits dargestellt. Mit 71,2\% ist der Katzenfloh auch der am häufigsten beim Hund vorkommende Floh, gefolgt vom Igefloh mit $14,7 \%$. Der Hundeloh spielt mit $3,4 \%$ nur eine untergeordnete Rolle [186]. Hunde sind das Hauptreservoir von Bartonella vinsonii subsp. berkhoffii, Bartonella henselae, Bartonella clarridgeiae, Bartonella washoensis, Bartonella elisabethae und Bartonella quintana [31]. Die Übertragung von Bartonellaspezies durch Hunde steht nicht im Vordergrund, vielmehr ihre Bedeutung als „sentinels“ einer Bartonellainfektion des Menschen [31]. Hunde sind auch wichtiges Reservoir der viszeralen Leishmaniose [181] und Überträger von Microsporum canis. An dermatologisch relevante Helminthosen durch Hunde sollte ebenfalls gedacht werden, wie Larva migrans cutanea durch eingedrungene Larven des Hundehakenwurms.

\section{Erregerübertragung durch exotische Haustiere}

In den USA werden in Haushalten etwa 40000 Igel der Spezies Atelerix albiventris (afrikanischer Igel) gehalten. Sie gelten als Überträger von Samonellen und Dermatophyten, insbesondere Trichophyton mentagrophytes var. erinacei [145]. Über einen ungewöhn- lichen Fall von Kerion durch Trichophyton erinacei wurde berichtet [80]. Durch Hypersensitivität auf Speichelantigene des Igels, die sich auf den Stacheln befinden, kann auch eine Kontakturtikaria auftreten [48]. Der europäische Igel (Erinaceus europaeus) wurde als Überträger von Mykobakterien (Mycobacterium marinum und Mycobacterium avium intracellulare) erkannt [145].

In Mode gekommen ist bei der Reptilienhaltung der Leguan (Iguana iguana) (Abb. 6). Allein in den USA werden 700000 als Haustiere gehalten [145]. Auch der Leguan ist Überträger von Salmonellen. Durch Leguanbisse kann eine Infektion mit Serratia marcescens auftreten, die zu phlegmonösen Hautveränderungen und systemischer Toxizität führen kann.

Ein weiteres Haustier mit Erregerübertragungspotential ist der Chinchilla. In den USA werden 80000 als Haustiere gehalten. Im Fell von Chinchillas wurden Trichophyton mentagrophytes und Microsporum gypseum nachgewiesen [20]. Chinchillas neigen auch zur Besiedlung von Klebsiella pneumonia und Pseudomonas aeruginosa.

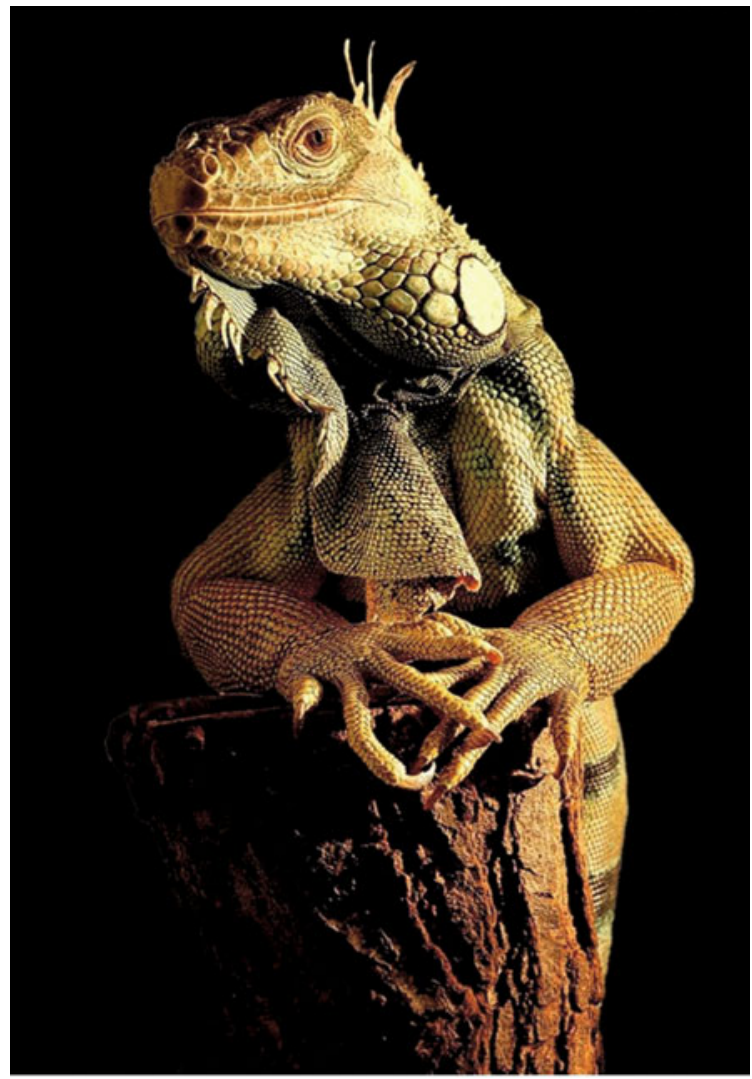

Abb. 6. Leguan (Iguana iguana) 
Der Kakadu, ein Verwandter des Papageien, ist wie die Taube eine Infektionsquelle von Cryptcoccus neoformans. Der Pilz wird über Fäzes ausgeschieden und kontaminiert die Käfige und die Umgebungsluft. Vögel können darüber hinaus Vogelmilben wie Ornithonyssus sylvarium und Dermanyssus gallinae verbreiten, deren Stiche zu stark juckenden papulovesikulären Arthropodenreaktionen führen.

Immunsupprimierte und HIV-Patienten sollten exotische Haustiere aus prophylaktischen Gründen meiden.

\section{Orf}

Orf, Ecthyma contagiosum, ist eine seltene virale Dermatose, die durch ein dermatotropes DNA Parapoxvirus aus der Familie der Poxviridae hervorgerufen wird. Diese Zoonose wird meist durch berufsbedingten Kontakt von Landwirten, Tierärzten und Metzgern mit erkrankten Schafen oder Ziegen erworben. Kürzlich wurde auch über das vermehrte Auftreten von Orf bei türkischen Hausfrauen berichtet, die sich beim traditionellen Opferfest mit erkrankten Schafen und Ziegen an den Händen infiziert hatten [179]. Seltene Überträger von Orf sind Rinder, Kamele und Rotwild [91].

\section{Zusammenfassung}

Innerhalb der letzten Jahre sind zahlreiche neue Erkenntnisse über dermatologisch relevante Zoonosen mitgeteilt worden. Durch Ferntourismus, Globalisierung, Migration, Klimawandel, Änderungen der Tierhaltung, Haltung exotischer Haustiere unter anderem sind Veränderungen im Erregerspektrum, in der Verteilung der Vektoren als auch im klinischen Bild von Zoonosen aufgetreten [43]. Neue Erkrankungen wie BSE, SARS und die aviäre Influenza H5N1 weisen auf die schnelle Änderung epidemiologischer Verhältnisse hin. Von den Zoonosen spielen die durch Arthropoden übertragenen Erkrankungen für die Dermatologie die größte Rolle [163]. Arthropoden von dermatologischer Bedeutung sind Arachnida (Zecken, Milben, Spinnen und Skorpione) sowie Insecta (Läuse, Flöhe, Wanzen, Hymenoptera, Fliegen, Mücken, Bremsen und Ameisen). Für den Hautarzt sind aktuelle Kenntnisse der Diagnostik, Behandlung, Prävention, Epidemiologie und biologischen Kontrolle arthropoden-vermittelter Erkrankungen und durch Haustiere übertragene Zoonose-Erreger von praktischer Bedeutung [42, 111].

\section{Literatur}

1. Alarcon A, Villanueva JL, Viciana P, et al. (2003) Q fever: epidemiology, clinical features and prognosis. A study from 1983 to 1999 in the South of Spain. J Infect 47: 110-116

2. Anonymous (2002) Tularemia - United States, 1990-2000. MMWR Morb Mortal Wkly Rep 51: 181-184

3. Asada H, Saito-Katsuragi M, Niizeki H, et al. (2005) Mosquito salivary gland extracts induce EBV-infected NK cell oncogenesis via CD4+ T cells in patients with hypersensitivity to mosquito bites. J Invest Dermatol 125: 956-961

4. Bacon RM, Biggerstaff BJ, Schriefer ME, et al. (2003) Serodiagnosis of Lyme disease by kinetic enzyme-linked immunosorbent assay using recombinant VlsE1 or peptide antigens of Borrelia burgdorferi compared with 2-tiered testing using whole-cell lysates. J Infect Dis 187: 1187-1199

5. Bakken JS, Krueth J, Wilson-Nordskog C, et al. (1996) Clinical and laboratory characteristics of human granulocytic ehrlichiosis. JAMA 275: 199-205

6. Barrett PN, Schober-Bendixen S, Ehrlich HJ (2003) History of TBE vaccines. Vaccine 21: S41-S49

7. Bartels CL, Peterson KE, Taylor KE (2001) Head lice resistance: itching that just won't stop. Ann Pharmacother 35: 109-112

8. Berger BW, Johnson RC, Kodner C, Coleman L (1995) Cultivation of Borrelia burgdorferi from human tick bite sites: a guide to the risk of infection. J Am Acad Dermatol 32: 184-187

9. Bircher AJ (2005) Systemic immediate allergic reactions to arthropod stings and bites. Dermatology 210: 119-127

10. Blanco JR, Oteo JA (2002) Human granulocytic ehrlichiosis in Europe. Clin Microbiol Infect 8: 763-772

11. Boulouis HJ, Chang CC, Henn JB, et al. (2005) Factors associated with the rapid emergence of zoonotic Bartonella infections. Vet Res 36: 383-410

12. Bradley M, Kutz SJ, Jenkins E, O'Hara TM (2005) The potential impact of climate change on infectious diseases of Arctic fauna. Int J Cicumpolar Health 64: 468-477

13. Brouqui P, Stein A, Dupont HT, et al. (2005) Ectoparasitism and vector-borne diseases in 930 homeless people from Marseille. Medicine 84: 61-68

14. Bundesverband Zeckenkankheiten (2006) http://www. bzk-online.de/

15. Burke GS, Wikel SK, Spielman A, et al. and the Tick-borne Infection Study Group (2005) Hypersensitivity to ticks and Lyme disease risks. Emerg Infec Dis 11: 36-41

16. Burkhart CN, Burkhart CG (2000) Oral ivermectin therapy for phthiriasis palpebrarum. Arch Ophthalmol 118: 134-135

17. Burkhart CG, Burkhart CN (2004) Oral ivermectin for Phthirus pubis. J Am Acad Dermatol 51: 1037-1038

18. Burkhart CN, Burkhart CG (2005) Head lice: Scientific assessment of the nit sheath with clinical ramifications and therapeutic options. J Am Acad Dermatol 53: 129-133

19. Burkhart CG, Burkhart CN (2006) Safety and efficacy of pediculicides for head lice. Expert Opin Drug Saf 5: 169-179

20. Cabanas FJ, Abarca ML, Bragulat MR (1997) Dermatophytes from domestic animals in Barcelona, Spain. Mycopathologica 137: 107-113

21. Canyon DV, Speare R, Muller R (2002) Spatial and kinetic factors for the transfer of head lice (Pediculus capitis) between hairs. J Invest Dermatol 119: 629-631

22. Cerimele F, Battle T, Lynch R, et al. (2005) Reactive oxygen signaling and MAPK activation distinguish Epstein-Barr Virus (EBV)-positive versus EBV-negative Burkitt's lymphoma. Proc Natl Acad Sci USA 102: 175-179 
23. Cerny Z (1994) Skin manifestations of tularemia. Int J Dermatol 33: 468

24. Cinco M, Luzzati R, Mascioli M, et al. (2006) Serological evidence of Rickettsia infections in forestry rangers in NorthEastern Italy. Clin Microbiol Infect 12: 493-495

25. Chapman AS, Bakken Folk SM, Paddock CD, et al. and Tickborne Rickettsial Diseases Working Group; CDC (2006) Diagnosis and management of tickborne rickettsial diseases: Rocky Mountains spotted fever, ehrlichioses, and anaplasmosis - United States: a pratical guide for physicians and other health-care and public health professionals. MMWR Reomm Rep 31: 1-27

26. Chappard C, Sainte-Laudy J, Emonot A (1996) Anaphylactic reactions caused by a pigeon's parasite (Argas reflexus). Biomed Res 7: 11-14

27. Charpin C, Mata P, Charpin D, et al. (1991) Fel d I allergen distribution in cat fur and skin. J Allergy Clin Immunol 88: $77-82$

28. Charpin C, Zielonka TM, Charpin D, et al. (1994) Effects of castration and testosterone on Fel d I production by sebaceous glands of male cats: II-Morphometric assessment. Clin Exp Allergy 24: 1174-1178

29. Charrel RN, Attoui H, Butenko AM, et al. (2004) Tick-borne virus diseases of human interest in Europe. Clin Microbiol Infect: 10: 1040-1055

30. Chiang AK, Tao Q, Srivastava G, Ho FC (1996) Nasal NK- and T-cell-lymphomas share the same type of Ebstein-Barr virus latency as nasopharyngeal carcinoma and Hodgkin's disease. Int J Cancer 68: 285-290

31. Chomel BB, Boulouis H-J, Maruyama S, Breitschwerdt EB (2006) Bartonella spp. In pets and effect on human health. Emerg Infect Dis 12: 389-394

32. Dautel H, Kahl O, Knülle W (1991) The soft tick Argas reflexus (F.) (Acari, Argasidae) in urban environments and its medical significance in Berlin (West). J Appl Entomol 111: 380-390

33. Dautel H, Dippel C, Oehme R, et al. (2006) Evidence for an increased geographical distribution of Dermacentor reticulatus in Germany and detection of Rickettsia sp. RpA4. Int J Med Microbiol 296: S1, 149-156

34. de Lima Barros MB, de Oliveira Schubach A, Francesconi do Valle AC, et al. (2004) Cat-transmitted sporotrichosis epidemic in Rio de Janeiro, Brazil: description od a series of cases. CID 38: 529-535

35. De Maeseneer J, Blokland I, Willems S, et al. (2000) Wet combing versus traditional scalp inspection to detect head lice in schoolchildren: observational study. BMJ 321: 11871188

36. Dobler G, Wolfel R, Schmuser H, et al. (2006) Seroprevalence of tick-borne and mosquito-borne arboviruses in European brown hares in Northern and Western Germany. Int J Med Microbiol 296: Suppl 1: 80-83

37. Downs AM, Stafford KA, Harvey I, Coles GC (1999) Evidence for double resistance to permethrin and malathion in head lice. Br J Dermatol 141: 508-511

38. Dourmishev AL, Dourmishev LA, Schwartz RA (2005) Ivermectin: pharmacology and application in dermatology. Int J Dermatol 44: 981-988

39. Drancourt M, Mainardi JL, Brouqui, Vandenesch F, et al. (1995) Bartonella (Rochalimaea) quintana endocarditis in three homeless men. N Engl J Med 332: 419-423

40. Dumler SJ (2002) Q fever. Curr Treat Options Infect Dis 4: 437-445
41. Eastman RT, Barrett LK, Dupuis K, et al. (2005) Leishmania inactivation in human pheresis platelets by a psoralen (amotosalen $\mathrm{HCl}$ ) and long-wavelength ultraviolet irradiation. Transfusion 45: 1459-1463

42. Elston DM (2004) Prevention of arthropod-related disease. J Am Acad Dermatol 51: 947-954

43. Elston DM (2005) New and emerging infectious diseases. J Am Acad Dermatol 52: 1062-1068

44. Enderlin G, Morales L, Jacos RF, Cross JT (1994) Streptomycin and alternative agents for the treatment of tularemia: review of the literature. Clin Infect Dis 19:42-47

45. Enk CD, Gardlo K, Hochberg M, et al. (2003) Kutane Leishmaniose. Hautarzt 54: 506-512

46. Enk CD, Fritsch C, Jonas F, et al. (2003) Treatment of cutaneous leishmaniosis with photodynamic therapy. Arch Dermatol 139: 432-434

47. Evans ME, Gregory DW, Schaffner W, McGee ZA (1985) Tularemia: a 30-year experience with 88 cases. Medicine (Baltimore) 64: 251-269

48. Fairley JA, Suchnaik J, Paller AS (1999) Hedgehog hives. Arch Dermatol 135: 561-563

49. Fingerle V, Goodman JL, Johnson RA, et al. (1997) Human granulocytic ehrlichiosis in Southern Germany: increased seroprevalence in high-risk goups. J Clin Microbiol 35: 32443247

50. Fölster-Holst R, Rufli T, Christophers E (2000) Die Skabiestherapie unter besonderer Berücksichtigung des früher Kindesalters, der Schwangerschaft und Stillzeit. Hautarzt 51: 7-13

51. Foil L, Andress E, Freeland RL, et al. (1998) Experimental infection of domestic cats with Bartonella henselae by inoculation of Ctenocephalides felis (Siphonaptera: Pulicidae) feces. J Med Entomol 35: 625-628

52. Foucault C, Ranque S, Badiaga S, et al. (2006) Oral ivermectin in the treatment of body lice. J Infect Dis 193: 474-476

53. Fournier P, Marrie TJ, Raoult D (1998) Diagnosis of Q fever. J Clin Microbiol 36: 1823-1834

54. Fournier PE, Grunnenberger F, Jaulhac B, et al. (2000) Evidence of Rickettsia helvetica infection in humans, Eastern France. Emerg Infect Dis 6: 389-392

55. Fournier PE, Allombert C, Supputamongkol Y, et al. (2004) An eruptive fever associated with antibodies to Rickettsia helvetica in Europe and Thailand. J Clin Microbiol 42: 816818

56. Fournier PE, Gouriet F, Brouqui P et al. (2005) Lymphangitis associated rickettsiosis caused by Rickettsia sibirica mongolotimonae: seven new cases and review of the literature. Clin Infec Dis 40: 1435-1444

57. Glatz M, Helmut K, Muellegger RR (2005) Molecular detection of Anaplasma phagocytophilum and Borrelia burgdorferi in Ixodes ricinus ticks from Austria. J Invest Dermatol 124: A126, Abstract 752

58. Glaziou P, Nyguyen LN, Moulia-Pelat JP, et al. (1994) Efficacy of ivermectin for the treatment of head lice (Pediculosis capitis). Trop Med Parasitol 45: 253-254

59. Groß U, Roos T, Friese K (2001) Toxoplasmose in der Schwangerschaft. Deutsch Ärztebl 98: A3293-A3300

60. Guibal F, de La Salmoniere P, Rybojad M, et al. (2001) High seroprevalence to Bartonella quintana in homeless patients with cutaneous parasitic infections in downtown Paris. J Am Acad Dermatol 44: 219-223

61. Haenssle HA, Kiessling J, Kempf VAJ, et al. (2006) Orthopoxvirus infection transmitted by a domestic cat. J Am Acad Dermatol 54: S1-S4 
62. Haglund M, Günther G (2003) Tick-borne encephalitis - pathogenesis, clinical course and long-term follow-up. Vaccine 21: S11-S18

63. Hamm H, Beiteke U, Höger PH, et al. (2005) Therapie der Skabies mit 5\%iger Permethrin-Creme: Ergebnisse einer deutschen multizentrischen Studie. JDDG 4: 407-413

64. Hassler D, Oehme R, Kimmig P, Dobler G (2003) Eyach-Virus: Verwandter des Colorado-Zeckenfieber-Virus in BadenWürtemberg wiederentdeckt. Dtsch Med Wochenschr 128: 1874

65. Haustein U-F (1991) Pyrethrine und Pyrethroide (Permethrin) bei der Behandlung von Skabies und Pediculosis. Hautarzt 42: 9-15

66. Hayasaka D, Goto A, Yoshii K, et al. (2001) Evaluation of European tick-borne encephalitis virus vaccine against recent Siberian and far-eastern subtype strains. Vaccine 19: 47744779

67. Hecking-Veltman J, Tenter AM, Daugschies A (2001) Studien zur Parasitenfauna bei Katzen im Raum Mönchengladbach. Prakt Tierarzt 82: 563-569

68. Hidano A, Kawakami M, Yago A (1982) Hypersensitivity to mosquito bite and malignant histocytosis. Jpn J Exp Med 52: 303-306

69. Hildebrandt A, Schmidt KH, Wilske B, et al. (2003) Prevalence of four species of Borrelia burgdorferi sensu lato and coinfection with Anaplasma phagocytophila in Ixodes ricinus ticks in central Germany. Eur J Clin Microbiol Infect Dis 22: 364-367

70. Hilger C, Bessot JC, Hutt N, et al. (2005) IgE-mediated anaphylaxis caused by bites of the pigeon tick Argas reflexus: cloning and expression of the major allergen Arg r 1. J Allerg Clin Immunol 115: 617-622

71. Hofmann H, Kunz C, Heinz FX, Dippe H (1983) Detectability of IgM antibodies against TBE virus after natural infection and after vaccination. Infection 11: 164-166

72. Hunfeld KP, Lambert A, Kampen H, et al. (2002) Seroprevalence of Babesia infections in humans exposed to ticks in Midwestern Germany. J Clin Microbiol 40: 2431-2436

73. Ibarra V, Blanco JR, Portillo A, et al. (2005) Effect of antibiotic treatment in patients with DEBONEL/TIBOLA. Ann N Y Acad Sci 1063: 257-258

74. Ibarra V, Portillo A, Santibanez S, et al. (2005) DEBONEL/ TIBOLA: is Rickettsia slovaca the only etiological agent? Ann N Y Acad Sci 1063: 346-348

75. Ishihara S, Ohshima K, Tokura Y, et al. (1997) Hypersensitivity to mosquito bites conceals clonal lymphoproliferation of Epstein-Barr viral DNA-positive natural killer cells. Jpn J Cancer Res 88: 82-87

76. Izri A, Chosidow O (2006) Efficacy of machine laundering to eradicate head lice: recommendations to decontaminate washable clothes, linens, and fomites. Clin Infect Dis 42: e9-10

77. Jackson LA, Spach DH, Kippen DA, et al. (1996) Seroprevalence to Bartonella quintana among patients at a community clinic in downtown Seattle. J Infect Dis 173: 1023-1026

78. Jacobs RF, Condrey YM, Yamauchi T (1985) Tularemia in adults and children: a changing presentation. Pediatrics 76 : 818-822

79. Jacobs RF (1996) Tularemia. Adv Pediatr Infect Dis 12: $55-69$

80. Jury CS, Lucke TW, Bilsland D (1999) Trichophyton erinacei: an unusual cause of Kerion. Br J Dermatol 141: 606-607

81. Kaiser L, Gronlund H, van Hag-Hamsten M, Achour A (2005) Crystallization and preliminary crystallographic data of a Fel d1 $(1+2)$ construct corresponding to the major allergen from cat. Acta Crystallograph Sect F Struct Biol Cryt Commun 61(pt2) 232-234

82. Kazar J (2005) Coxiella burnetii infection. Ann NY Acad Sci 1063: 105-114

83. Kipp S, Goedecke A, Dorn W, et al. (2006) Role of birds in Thuringia, Germany, in the natural cycle of Borrelia burgdorferi sensu lato, the Lyme disease spirochaete. Int J Med Microbiol 296 Suppl 1: 125-128

84. Kleine-Tebbe J, Heinatz A, Gräser I, et al. (2006) Bites of the European pigeon tick (Argas reflexus): Risk of IgE-mediated sensitizations and anaphylactic reactions. J Allergy Clin Immunol 117: 190-195

85. Ko CJ, Elston DM (2004) Pediculosis. J Am Acad Dermatol 50: $1-12$

86. Koehler JE, Sanchez MA, Garrido CS (1997) Molecular epidemiology of Bartonella infections in patients with bacillary angiomatosis-peliosis. N Engl J Med 337: 1876-1883

87. Koehler JE, Sanchez MA, Tye S, et al. (2003) Prevalence of Batonella infection among human immunodeficiency virus-infected patients with fever. Clin Infect Dis 37: 559-566

88. Kohl H, Kühr H (2005) Klimawandel auf der Erde - die planetare Krankheit. Spektrum der Wissenschaft, Dossier 2/05: 24-31

89. Krause PJ, Telford SR III, Spielman A, et al. (1996) Concurrent Lyme disease and babesiosis: evidence for increased severity and duration of illness. JAMA 275: 1657-1660

90. Krause PJ, McKay K, Thompson CA, et al. and Deer-Associated Infection Study Group (2002) Disease specific diagnosis of co-infecting tick-borne zoonoses: babesiosis, human granulocytic ehrlichiosis, and Lyme disease. Clin Infect Dis 34: 11841191

91. Kuhl JT, Huerter CJ, Hashish H (2003) A case of human Orf contracted from a deer. Cutis 71: 288-290

92. Lakos A (1997) Tick-borne lymphadenopathy - a new rickettsial disease? Lancet 4: 1006

93. Lakos A (2002) Tick-borne lymphadenopathy (TIBOLA). Wien Klin Wochenschr 114: 648-654

94. La Scola B, Raoult D (1997) Laboratory diagnosis of rickettsioses: current approaches to diagnosis of old and new rickettsial diseases. J Clin Microbiol 35: 2715-2727

95. Lespine A, Dupuy J, Orlowski S, et al. (2006) Interaction of with multidrug resistance proteins (MRP1, 2 and 3). ChemicoBiological Interactions 159: 169-179

96. Leverkus M, Jochim RC, Schäd S, et al. (2006) Bullous allergic hypersensitivity to bed bug bites mediated by IgE againt salivary nitrophorin. J Invest Dermatol 126: 91-96

97. Liang FT, Philipp MT (1999) Analysis of antibody response to invariable regions of VLsE, the variable surface antigen of Borrelia burgdorferi. Infect Immun 67: 6702-6706

98. Liang FT, Steere AC, Marques AR, et al. (1999) Sensitive and specific serodiagnosis of Lyme disease by enzyme-linked immunosorbent assay with a peptide based on an immunodominant conserved region of Borrelia burgdorferi VlsE. J Clin Microbiol 37:3990-3996

99. Liang FT, Aberer E, Cinco M, et al. (2000) Antigenic conservation of an immunodominant invariable region of the VlsE lipoprotein among European pathogenic genospecies of Borrelia burgdorferi sl. J Infect Dis 182: 1455-1462

100. Lindgren E, Talleklint L, Polfeldt $T$ (2000) Impact of climatic change on the northern latitude limit and population density of the disease-transmitting European tick Ixodes ricinus. Environ Health Perspect 108: 119-123 
101. Lindgren E, Gustafson R (2001) Tick-borne encephalitis in Sweden and climate change. Lancet 358: 16-18

102. Lledo L, Gegundez MI, Fernandes N, et al. (2006) The seroprevalence of human infection with Rickettsia slovaca, in an area of Northern Spain. Ann Trop Med Parasitol 100: 337-343

103. Lord WD, DiZinno JA, Wilson MR, et al. (1998) Isolation, amplification and sequencing of human mitochondrial DNA obtained from human crab louse, Phthirus pubis, blood meals. J Forensic Sci 43: 1097-1100

104. Lundkvist K, Vene S, Golovljova I, et al. (2001) Charaterization of tick-borne encephalitis virus from Latvia: evidence for cocirculation of three distinct subtypes. J Med Virol 65: 770735

105. Maetzel D, Maier WA, Kampen H (2005) Borrelia burgdorferi infection prevalences in questing Ixodes ricinus ticks (Acari: Ixodidae) in urban and suburban Bonn, western Germany. Parasitol Res 95: 5-12

106. Marrie TJ, Raoult D (1997) Q fever - a review and issues for the next century. Int J Antimicrob Agents 8: 145-161

107. Martinod S, Gilot B (1991) Epidemiology of canine babesiosis in relation to the activity of Dermacentor reticulatus in southern Jura (France). Exp Appl Acarol 11: 215-222

108. Maurin M, Raoult D (1999) Q-fever. Clin Microbiol Rev 12: 518-553

109. Mavris M, Halos L (2005) Third Congress for the European Society for Emerging Infections (conference summary) Emerging Infectious Diseases 11, April

110. Mazloumi Gavgani AS, Hodjati MH, et al. (2002) Effect of insecticide-impregnated dog collars on incidence of zoonotic visceral leishmaniasis in Iranian children: a matched cluster randomized trial. Lancet 360: 374-379

111. Mehlhorn H (2001) (ed) Encyclopedic reference of parasitology, $2^{\text {nd }}$ ed., Vol 1, 2, Springer, Heidelberg

112. Mehlhorn B, Mehlhorn H (Hrsg) Zecken, Milben, Fliegen, Schaben, Schach dem Ungeziefer. Springer, Heidelberg, 3. Aufl., 2001

113. Mehlhorn H, Piekarski G (Hrsg) Grundriss der Parasitenkunde. 6. Aufl., Spektrum, Elsevier, Heidelberg, 2003

114. Mehlhorn H, Köhler S (Hrsg) CD: Reiseerkrankungen, Schädlinge und Parasiten. Ungeliebte Begleiter auf Reisen und zu Hause. Alpha-Biocare Medienservice Düssldorf, 2004

115. Meinking T, Burkhart CN, Burkhart CN (2002) Head lice (letter). New Engl J Med 347: 1381-1382

116. Meinking TL, Clineschmidt CM, Chen C, et al. (2002) An observer-blinded study of $1 \%$ permethrin creme rinse with and without adjunctive combing in patience with head lice. J Pediatr 141: 665-670

117. Miadonna A, Tedeschi A, Leggieri A, et al. (1982) Anaphylactic shock caused by allergy to the venom of Argas reflexus. Ann Allergy 49: 293-294

118. Mounsey KE, Holt DC, McCathy J, Walton SF (2006) Identification of $\mathrm{ABC}$ transporters in Sacoptes scabiei. Parasitology 3: $1-10$

119. Müllegger RR (2004) Dermatological manifestations of Lyme borreliosis. Eur J Dermatol 14: 296-30

120. Mumcuoglu KY, Friger M, Ioffe-Uspensky I, et al. (2001) Louse comb versus direct visual examination for the diagnosis of head louse infestations. Pediatr Dermatol 18: 9-12

121. Mumcuoglu KY (2006) Effective treatment of head louse with pediculocides. J Drugs Dermatol 5: 451-452

122. Murakami MT, Freitas Fernandes-Pedrosa M, de Andrale SA, et al. (2006) Structural insights into the catalytic mechanism of sphingomyelinase D and evolutionary relationship to glycero- phosphodiester phoshodiesterases. Biochem Biophys Res Commun 342: 323-329

123. Murray HW, Berman JD, Davies CR, Saravia NG (2005) Advances in leishmanisasis. Lancet 366: 1561-157

124. Nicholson WL, Comer JA, Sumner JW, et al. (1997) An indirect immunofluorescence assay using cell culture-derived antigen for detection of the agent of human granulocytic ehrlichiosis. J Clin Micobiol 35: 1510-1516

125. Nilsson K, Lukinius A, Pahlson C, et al. (2005) Evidence of Rickettsia spp. infection in Sweden: a clinical ultrastructural and serological study. Acta Pathol Microbiol Immunol Scand 113: $126-134$

126. Ohguchi H, Hirabayashi Y, Kodera T, et al. (2006) Q fever with clinical features resembling systemic lupus erythematodes. Intern Med. 45: 323-326

127. Paixao-Cavalcante D, Van den Berg CW, Fernandes-Pedrosa $\mathrm{M}$ de F, et al. (2006) Role of matrix metalloproteinases in HaCaT keratinocytes apoptosis induced by Loxoseles venom sphingomyelinase D. J Invest Dermatol 126: 61-68

128. Parker NR, Barralet JH, Bell AM (2006) Q fever. Lancet 367: 679-688

129. Parola P, Raoult D (2001) Ticks and tick-borne bacterial diseases in humans: an emerging infectious threat. Clin Infect Dis 32: 897-928

130. Paul J, Bates J (2000) Is infestation with the common bedbug increasing? BMJ 320:1141

131. Petrovc M, Lotric FS, Zupanc TA, et al. (1997) Human disease in Europe caused by a granulocytic Ehrlichia species. J Clin Microbiol 35: 1556-1559

132. Pfister K (2006) Arthropodenbefall bei Wiederkäuern. In: Schnieder T (Hrsg) Veterinärmedizinische Parasitologie, Parey, Stuttgart, S 235-258

133. Pfister K (2006) In: Schnieder T (Hrsg) Arthropodenbefall bei Hund und Katze. Veterinärmedizinische Parasitologie, Parey, Stuttgart, S 521-560

134. Pierzchalski JL, Bretl DA, Matson SC (2002) Phthirus pubis as a predictor for chlamydia infections in adolescents. Sex Transm Dis 29: $331-334$

135. Purvis RS, Tyring SK (1991) An outbrake on lindane-resistant scabies treated successfully with permethrin $5 \%$ cream. J Am Acad Dermatol 25: 1015-1016

136. Quaterman MJ, Lesher JL (1994) Neonatal scabies treated with Permethrin 5\% cream. Pediatr Dermatol 11: 264-266

137. Quercia O, Emiliani F, Foschi FG, Stefanini GF (2005) Anaphylactic shock to Argbite. Allerg Immunol (Paris) 37: 66-68

138. Randolph SE (2001) The shifting landscape of tick-borne zoonoses: tick-borne encephalitis and Lyme borreliosis in Europe. Phil Trans Roy Soc (London), Series B, 356: 10451056

139. Randolph SE (2004) Evidence of climate change has caused "emergence" of tick-borne diseases in Europe? Int J Med Microbiol 293: S5-S15

140. Raoult D, Lakos A, Fennolar F, et al. (2002) Spotless rickettsiosis caused by Rickettsia slovaca and associated with Dermacentor ticks. Clin Infec Dis 34: 1331-1336

141. Reithinger R, Mohsen M, Wahid M, et al. (2005) Efficacy of thermotherapy to treat cutaneous leishmaniasis caused by Leishmania tropica in Kabul, Afghanistan: a randomized, controlled trial. CID 40: 1148-1155

142. Ribeiro JM, Francisschetti MB (2003) Role of arthropod saliva in blood feeding: sialome and post-sialome perspectives. Annu Rev Entomol 48: 73-88 
143. Richter J, Stöver IM, Walter S, et al. (2005) Kopfläuse - Umgang mit einer wieder auflebenden Parasitose. Dtsch Ärztebl 102: A2395-A2398

144. Rogers ME, Ilg T, Nikolaev AV, et al. (2004) Transmission of cutaneous leishmaniasis by sand flies is enhanced by regurgitation of fPPG. Nature 430: 463-467

145. Rosen T, Jablon J (2003) Infectious threats from exotic pets: dermatological implications. Dermatol Clin 21: 229-236

146. Roux V, Raoult D (1999) Body lice as tools for diagnosis and surveillance of reemerging diseases. J Clin Microbiol 37: 596599

147. Sasaki T, Kobayashi M, Agui N (2002) Detection of Bartonella quintana from body lice (Anoplura: Pediculidae) infesting homeless people in Tokyo by molecular technique. J Med Entomol 39: 427-429

148. Sasaki T, Poudel SK, Isawa H, et al. (2006) First molecular evidence of Bartonella quintana in pediculus humanus capitis (Phthiraptera: Pediculidae), collected from Nepalese children. J Med. Entomol 43: 110-112

149. Satoh M, Oyama N, Akiba H, et al. (2002) A case of hypersensitivity to mosquito bites with natural-killer cell lymphocytosis: the possible implication of Epstein-Barr virus reactivation. Eur J Dermatol 12: 381-384

150. Schouls LM, Van de Pol I, Rijpkema SG, Schot CS (1999) Detection and identification of Ehrlichia, Borrelia burgdorferi sensu lato and Bartonella species in Dutch Ixodes ricinus ticks. J Clin Microbiol 37: 2215-2222

151. Schubach TM, Valle AC, Gtierez-Galhardo MC, et al. (2001) Isolation of Sporothrix schenckii from the nails of domestiv cats (Felis catus). Med Mycol 39: 147-149

152. Schubach AO, Schubach TM, Barros MB (2005) Epidemic cat-transmitted sporotrichosis. N Engl J Med 353: 11851186

153. Seppala U, Hagglund P, Wurtzen PA, et al. (2005) Molecular characterization of the major cat allergen Fel d1: expression of heterodimer by use of a baculovirus expression system. J Biol Chem 280: 3208-3216

154. Shani-Adir A, KamilS, Rozenma D, et al. (2005) Leishmania tropica in Northern Israel: a clinical overview of an emerging focus. J Am Acad Dermatol 53: 810-815

155. Simser JA, Palmer AT, Fingerle V, et al. (2002) Rickettsia monacensis sp. nov., a spotted fever goup Rickettsia, from ticks (Ixodes ricinus) collected in a European city park. Appl Environ Microbiol 68: 4559-4566

156. Singh S, Sivakumar R (2004) Challenges and new discoveries in the treatment of leishmaniasis. J Infect Chemother 10: 307315

157. Singh-Behl D, La Rosa SP, Tomecki KJ (2003) Tick-borne infections. Dermatol Clin 21: 237-244

158. Sirianni MC, Mattiacci G, Barbone B, et al. (2000) Anaphylaxis after Argas reflexus bite. Allergy 55: 303

159. Spach DH, Kanter AS, Dougherty MJ, et al. (1995) Bartonella (Rochalimaea) quintana bacteremia in inner-city patients with chronic alcoholism. N Engl J Med 332: 424-428

160. Speare R, Koehler JM (2001) A case of pubic lice resistant to pyrethrins. Austral Fam Phys 30: 572-574

161. Sréter-Lancz Z, Széll Z, Kovács G, et al. (2006) Rickettsiae of the spotted-fever group in ixodid ticks from Hungary: identification of a new genotype („Candidatus Rickettsia kotlanii“). Ann Trop Med Parasitol 100: 229-236

162. Stanczak J (2006) Detection of spotted fever group (SFG) rickettsiae in Dermacentor reticulatus (Acari: Ixodidae) in Poland. Int J Med Micobiol 296 Suppl 1: 144-148
163. Steen CJ, Carbonaro PA, Schwartz RA (2004) Arthropods in dermatology. J Am Acad Dermatol 50: 819-842

164. Steere AC, McHugh G, Suarez C et al. (2003) Prospective study of coinfection in patients with erythma migrans. Clin Infect Dis 36: 1078-1081

165. Stein A, Raoult D (1995) Return of trench fever. Lancet 345: 450-451

166. Schubach TM, de Oliveia Schubach A, dos Reis RS, et al. (2002) Sporothrix schenckii isolated from domestic cats with and without sporothrichosis in Rio de Janeiro, Brazil. Myopathologica 153: 83-86

167. Süss J, Schrader C, Abel U, et al. (1999) Annual and seasonal variation of tick-borne encephalitis virus (TBEV) prevalence in ticks in selected hot spot areas in Germany using RT-PCR: results from 1997 and 1998. Zentralbl Bakteriol 289: 564578

168. Süss J, Schrader C, Abel U, et al. (2002) Charaterization of tickborne encephalitis (TBE) foci in Germany and Latvia (19972000). Int J Med Microbiol 291 (suppl 33) 34-42

169. Takano-Lee M, Edman JD, Mullens BA, Clark JM (2005) Transmission potential of human head louse, Pediculus capitis (Anoplura: Pediculidae). Int J Dermatol 44: 811-816

170. Tambourgi DV, Paixao-Cavalcante D, Goncalves de Andrade RM, et al. (2005) Loxosceles sphingomyelinase induces complement-dependent dermonecrosis, neutrophil infiltration, and endogeneous gelatinase expression. J Invest Dermatol 124: 725-731

171. Taplin D, Meinking TL, Porcelain SL, et al. (1986) Permethrin $5 \%$ dermal cream: a new treatment for scabies. J Am Acad Dermatol 15: 995-1001

172. Tenter AM, Heckeroth AR, Weis LM (2000) Toxoplasma gondii: from animals to humans. Int J Parasitol 30: 1217-1258

173. Ter Poorten MC, Prose NS (2005) The return of the common bedbug. Pediatr Dermatol 22: 183-187

174. Tietz H-J, Czaika V, Ulbricht HM, Sterry W (1999) Tinea capitis in Germany. A survey in 1998. Myoses 42 (suppl 2) 73-76

175. Tissot Dupont H, Raoult D, Brouqui P, et al. (1992) Epidemiologic features and clinical presentation of acute Q fever in hospitalized patients: 323 French cases. Am J Med 93: 427434

176. Tokura Y, Tamura Y, Takigawa M, et al. (1990) Severe hypersensitivity to mosquito bites associated with natural killer cell lymphocytosis. Arch Dermatol 126: 362-368

177. Trautmann A, Amschler A, Schultz KD, et al. (1995) Anaphylaktische Reaktionen durch Taubenzecken. Dermatosen 42: 215-218

178. Tzenow I, Wehmeier M, Melnik B (1997) Orale Behandlung der Skabies mit Ivermectin. Hautarzt 48: 2-4

179. Uzel M, Sasmaz S, Bakaris S, et al. (2005) A viral infection of the hand commonly seen after the feast of sacrifice: human orf (orf of the hands). Epidemiol Infect 133: 653-657

180. Valenzuela JG, Ribeiro JM (1998) Purification and cloning of the salivary nitrophorin from the hemipteran Cimex lectularius. J Exp Biol 201 (part 18) 2659-2664

181. Vanloubbeeck Y, Jones DE (2004) The immunology of Leishmania infection and the implications for vaccine development. Ann N Y Acad Sci 1026: 267-272

182. Van Dobbenburgh A, Van Dam AP, Fikrig E (1999) Human granulocytic ehrlichiosis in Western Europe. N Engl J Med 340: $1214-1216$

183. Veraldi S, Scarabelli G, Grimalt R (1996) Acute urticaria caused by pigeon ticks (Argas reflexus). Int J Dermatol 35: 34 
184. Victoria J, Trujillo R (2001) Topical ivermectin: a new successful treatment for scabies. Pediatr Dermatol 18: 63-65

185. Vogel JP (2004) Turning a tiger into a house cat: using Legionella pneumophila to study Coxiella burnettii. Trends Micobiol 12: 103-105

186. Voigt T (2005) Flöhe - Gesundheitsrisiko für Mensch, Katze und Hund. Monatsschr Pharm 28: 427-434

187. Voigt TF (2006) Ixodes ricinus. Gesundheitsrisiken und Maßnahmen zur Prophylaxe. Med Monatsschr Pharm 29: 162-170

188. Von Loewenich FD, Baumgarten BV, Schroppel K, et al. (2003) High diversity of ankA sequences of Anaplasma phagocytophilum among Ixodes ricinus ticks in Germany. J Clin Microbiol 41: 5033-5040

189. Walker DH, Valbuena GA, Olano JP (2003) Pathogenic mechanisms of diseases caused by Rickettsia. Ann N Y Acad Sci 990: $1-11$

190. Weinberg GA (2001) Laboratoy diagnosis of ehrlichiosis and babesiosis. Pediatr Infect Dis 20: 435-437

191. Weisshaar E, Schaefer A, Scheidt RR, et al. (2006) Epidemiology of tick bites and borreliosis in children attending kindergarten or so-called „forest kindergarten“ in Southwest Germany. J Invest Dermatol 126: 584-590

192. White DJ, Talarico J, Chang HG, et al. (1998) Human babesiosis in New York State: Review of 139 hospitalized cases and analysis of prognostic factors. Arch Intern Med 158: 21492154

193. Wikel SK (1996) Host immunity to ticks. Annu Rev Entomol 41: 1-22

194. Williams LK, Reichert A, MacKenzie WR, et al. (2001) Lice, nits, and school policy. Pediatrics 107: 1011-1015

195. Woldehiwet Z (2004) Q fever (coxiellosis): epidemiology and pathogenesis. Res Vet Sci 77: 93-100

196. Wurzel LG, Cable RG, Leiby DA (2002) Can ticks spread hepatitis C virus? N Engl J Med 347: 1724-1725

197. Yamamoto T, Fujii K, Tsuji K, et al. (2005) Characterization of Epstein-Barr virus-infected natural killer lymphocytes in a patient with hypersensitivity to mosquito bites. J Am Acad Dermatol 53: 912-914

198. Young GD, Evans S (1998) Safety and efficacy of DEET and permethrin in the prevention of arthropod attack. Mil Med 163: $324-330$

199. Youssef MY, Sadaka HA, Eissa MM, El-Ariny AF (1995) Topical application of ivermectin for human ectoparasites. Am J Trop Med Hyg 53: 652-653

200. Zielonka TM, Charpin D, Berbis P, et al. (1994) Effects of castration and testosterone on Fel d I production by sebaceous glands and male cats: I - Immunological assessment. Clin Exp Allergy 24: 1169-1173 